\title{
Adjunction of the Lipase Inhibitor Orlistat Improves Grape Seed Extract Neuroprotection against Brain Ischemia/Reperfusion Injury in Rats
} \author{
Aouani ${ }^{2,4}$ \\ ${ }^{1}$ University of Tunis El Manar, Faculty of Sciences of Tunis, Tunis, TUNISIA. \\ ${ }^{2}$ Laboratory of Bioactive Substances, Center of Biotechnology of Borj-Cedria, Hammam-lif, TUNISIA. \\ ${ }^{3}$ Department of Biology, College of Science, University of Ha'il, KINGDOM OF SAUDI ARABIA. \\ ${ }^{4}$ University of Carthage, Faculty of Sciences of Bizerte, Zarzouna, TUNISIA.
}

Slim Ghrir ${ }^{1,2}$, Wassim Ben Abbes ${ }^{1,2}$, Kamel Charradi ${ }^{2, \star}$, Salem Elkahoui ${ }^{2,3}$, Ferid Limam², Ezzedine

\begin{abstract}
Aim: Stroke is a public health concern for which there is currently no prophylaxis. In this study, we assessed the protective effect of Grape Seed Extract (GSE) and Orlistat (ORL) against brain ischemia/reperfusion (I/R) injury. Methods: Adult male Wistar rats were treated either with GSE $(2.5 \mathrm{~g} / \mathrm{kg})$, ORL $(4 \mathrm{mg} / \mathrm{kg})$ or both drugs for one week and ischemia performed during $30 \mathrm{~min}$ by a bilateral common carotid artery occlusion (BCCAO), followed by $60 \mathrm{~min}$ reperfusion. Rats were then sacrificed, their whole brain used for infarct size determination using TTC staining or dissected into cortex, hippocampus and cerebellum for biochemical analysis of I/R-induced oxidative stress and energy failure. Results: In the three brain regions of interest, I/R disturbed protein carbonylation, xanthine oxidase (XO), catalase (CAT), glutathione peroxidase (GPx) and superoxide dismutase (SOD) activities, as well as intracellular mediators as hydrogen peroxide $\left(\mathrm{H}_{2} \mathrm{O}_{2}\right)$, calcium and iron. Furthermore I/R altered energy fueling through the decrease of $\alpha$-ketoglutarate dehydrogenase $(\alpha-K G D H)$ and fumarase (FH) together with mitochondrial complexes I and II along with glutamatergic excitotoxicity through glutamate dehydrogenase (GDH) and glutamine synthetase (GS) activities into cortex and hippocampal areas but not into cerebellum. In addition I/R affected mitochondrial viability as assessed by MTT staining and the moonlighting apoptosis inducer glyceraldehyde-3phosphate dehydrogenase (GAPDH). Conclusion: Interestingly, GSE prevented efficiently the deleterious effects of I/R and the best protection was obtained when combining the two drugs, especially within cortex and hippocampus compartments. Thus, adjunction of ORL to GSE treatment is a promising strategy to improve neuroprotection from stroke.
\end{abstract}

Key words: Brain I/R, GSE, Orlistat, Neuroprotection, Energy failure.

\section{INTRODUCTION}

Stroke is one of the leading causes of mortality and disability worldwide. ${ }^{1,2}$ In most cases, it consists in an occlusion of a cerebral artery caused by thrombosis or embolism. ${ }^{3}$ Ischemic stroke induces a pathophysiologic cascade characterized by energy failure, intracellular acidosis, disruption of $\mathrm{Na}^{+} / \mathrm{K}^{+}$ATPases, excitotoxicity, intracellular calcium overload and oxidative/nitrosative stress. These latter events cause deleterious brain damages as neurodegeneration, inflammation, endothelial dysfunction and loss of blood-brain barrier (BBB) integrity. ${ }^{4}$ At present reperfusion by thrombolysis or thrombectomy is the most straightforward way to protect the brain from infarction. However, restoration of cerebral blood flow may exacerbate ischemic damage and by this way worsening cerebral infarct size. $^{5}$ As the brain is highly vulnerable to reperfusion because of its high rate of oxidative metabolism, relative low antioxidant capacity and high content of polyunsaturated fatty acids, ${ }^{6}$ neuro-
Submission Date: 04-08-2020; Revision Date: 09-12-2020; Accepted Date: 17-03-2021

DOI: 10.5530/ijper.55.2.91 Correspondence: Dr. Kamel Charradi Laboratory of Bioactive Substances, Center of Biotechnology of Borj-Cedria, BP 901, Hammam-lif 2050, TUNISIA.

Phone no: +216 79325728 Email id: charradi3@yahoo. com

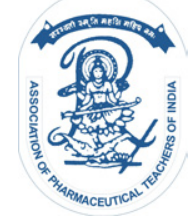

www.ijper.org 
prevention appears a promising approach to preserve the brain from I/R injury.

Grape seed extract (GSE) is a nutritional supplement that has been attributed the Generally Recognized As Safe (GRAS) certification from US Food and Drug Administration (FDA). ${ }^{7}$ GSE is a complex mixture of bioactive compounds including polyphenols such as flavonoids and proanthocyanidins. ${ }^{8}$ This potential health food ingredient is recognized as a mainstay in the prevention of metabolic syndrome pathologies as arterial hypertension, hyperlipidemia or hyperglycemia. ${ }^{9}$ It is also well documented that GSE exhibits a potent protective effect on various organs such as liver, kidney, heart and brain, partly by its anti-oxidative and anti-inflammatory properties. ${ }^{10-12}$ In particular our Lab recently showed that GSE exhibited potent neuroprotection against $\mathrm{I} / \mathrm{R}$ insult in a rat model of stroke partly by its antioxidative role but also by its ability to modulate key proteins involved in energy fueling and signal transduction. ${ }^{13,14}$

Orlistat (ORL) is an anti-obesity drug recently approved by US FDA as an over the counter medicine, which acts by decreasing fat absorption through inhibiting gastrointestinal lipases. ${ }^{15}$ ORL has also been shown to exert beneficial effects on carbohydrate and lipid metabolism ${ }^{16}$ improving cognitive capacity in a mice model of Alzheimer disease. ${ }^{17,18}$ We recently showed the efficiency of ORL when combined to GSE in protecting the brain from high fat diet-induced lipotoxicity in rats. ${ }^{19}$ In this work, we investigated the putative protection afforded by combining GSE and ORL on brain I/R injury with an emphasis on oxidative stress, energy failure and excitotoxicity into three main compartments i.e. cortex, hippocampus and cerebellum.

\section{MATERIALS AND METHODS}

\section{Drugs and reagents}

GSE was processed from a grape cultivar of Vitis vinifera cv. Carignan (2015) from Neferis winery Grombalia, Tunisia. Seeds were manually separated from skins, airdried and grounded until a fine powder was obtained. This latter was dissolved in $10 \%$ ethanol $(250 \mathrm{mg} / \mathrm{mL})$, vigorously vortexed for $10 \mathrm{~min}$ and centrifuged at 10,000 $\mathrm{g}$ for $15 \mathrm{~min}$ at $4^{\circ} \mathrm{C}$ to recover a supernatant containing soluble polyphenols. ORL (Xenical ${ }^{\circledR},(\mathrm{S})$-2-formylamino4-methyl-pentanoic acid (S)-1-[[(2S, 3S)-3-hexyl-4-oxo2-oxetanyl]methyl]-dodecyl ester) was obtained from Pharmalpa (France) and dissolved in 10\% ethanol (1.5 $\mathrm{mg} / \mathrm{mL}$ ). Adenosine 5'-diphosphate sodium salt (ADP), bovine catalase, bovine serum albumin (BSA),2,4dinitrophenylhydrazine (DNPH), epinephrine, ethylenediaminetetraacetic acid (EDTA), L-glutamate (Glu), L-glutamine (Gln), L-glutathione reduced (GSH), glyceraldehyde 3-phosphate (GA3P),hydrochloric acid $(\mathrm{HCl})$, iron (III) chloride hexahydrate $\left(\mathrm{FeCl}_{3}\right), \alpha$ ketoglutarate $(\alpha-\mathrm{kG})$, L-malate, $\beta$-nicotinamide adenine dinucleotide $\left(\mathrm{NAD}^{+}\right)$, sodium arsenite $\left(\mathrm{NaAsO}_{2}\right)$, sodium azide $\left(\mathrm{NaN}_{3}\right)$, succinic acid, sucrose, trichloroacetic acid (TCA), 2,3,5- triphenyl tetrazolium chloride (TTC), Tris base, urethane and xanthine were purchased from Sigma-Aldrich (Germany). 3-(4,5-Dimethylthiazol-2yl)-2,5-diphenyltetrazolium bromide (MT'T), dithio5,5'-bis(2-nitro-benzoic acid) (DTNB), $\beta$-nicotinamide adenine dinucleotide reduced $(\mathrm{NADH})$ and potassium ferricyanide $\left(\mathrm{K}_{3}\left[\mathrm{Fe}(\mathrm{CN})_{6}\right]\right)$ were obtained from Bio Basic (Canada). Guanidine hydrochloride ( $\mathrm{GuHCl})$ and mannitol were purchased from Pan Reac Applichem (Germany). Potassium cyanide (KCN), manganese (II) chloride tetrahydrate $\left(\mathrm{MnCl}_{2}\right)$, imidazole, hydroxylamine hydrochloride $\left(\mathrm{NH}_{2} \mathrm{OH}\right)$ were obtained from Prolabo (France), Merck (Germany), Affymetrix USB (USA) and Acros Organics (France), respectively. All other reagents were of analytical grade.

\section{Animals and experimental design}

One hundred twenty-eight male Wistar rats (213.5 \pm 41.2 g, $26.2 \pm 8.7$ week-old) from Pasteur Institute of Tunis were used in agreement with the National Ethic Committee of Tunis University for use and care of animals and with the National Institutes of Health guidelines (NIH Publications No. 80-23, revised in 1996). They were provided with food and water ad libitum and maintained in animal facility at a fixed temperature of $22 \pm 2^{\circ} \mathrm{C}$ with a $12 \mathrm{hr}$ light/dark cycle.

Rats were randomly divided into eight groups $(n=16$ per group) and daily treated during one week by intraperitoneal way (ip) as follows: (i) control group (C): receiving $10 \%$ ethanol, (ii) IR group: receiving $10 \%$ ethanol prior to IR, (iii) G group: receiving GSE (2.5 $\mathrm{g} / \mathrm{kg}$ ), (iv) GIR group: receiving GSE $(2.5 \mathrm{~g} / \mathrm{kg})$ prior to IR, (v) O group: receiving ORL (4 mg/ $\mathrm{kg}$ ), (vi) OIR group: receiving ORL (4 $\mathrm{mg} / \mathrm{kg}$ ) prior to IR, (vii) GO group: receiving GSE $(2.5 \mathrm{~g} / \mathrm{kg})$ and ORL $(4 \mathrm{mg} / \mathrm{kg})$ and (viii) GOIR group: receiving GSE $(2.5 \mathrm{~g} / \mathrm{kg})$ and ORL (4 mg/kg) prior to I/R.

\section{Induction of brain I/R injury}

Brain I/ $\mathrm{R}$ injury was induced using the transient global ischemia model described by Smith et al. (1984) ${ }^{20}$ with slight modification. Briefly, twenty-four hours after the last treatment, rats were anesthetized with urethane (1.2 $\mathrm{g} / \mathrm{kg}$ ). A midline ventral incision was realized in the neck and both common carotid arteries exposed with 
special attention paid to separating the vagus nerve. Ischemia was performed through a bilateral common carotid artery occlusion (BCCAO) with vascular clamps for $30 \mathrm{~min}$ followed by $60 \mathrm{~min}$ reperfusion. Arteries were visually inspected to confirm cessation and restoration of blood flow following ischemia and reperfusion, respectively. At the end of reperfusion, rats were sacrificed by decapitation and their whole brains were taken out for infarct size measurement $(n=4)$ or dissected into cortex, hippocampus and cerebellum for biochemical determination of oxidative stress and energy fueling disturbances $(n=12)$.

\section{Preparation of tissue homogenates}

The three brain regions of interest i.e. cortex, hippocampus and cerebellum $(n=6)$ were grounded in liquid nitrogen and homogenized in phosphatebuffered saline $\mathrm{pH}$ 7.4. After centrifugation $(10,000 \mathrm{~g}$, $10 \mathrm{~min}, 4^{\circ} \mathrm{C}$ ), supernatants were collected and proteins quantified using a commercially available kit from Biomaghreb according to the Biuret method. ${ }^{21}$

\section{Preparation of cytosolic and mitochondrial fractions}

Cytosolic and mitochondrial fractions were prepared as previously described by Liang and Patel (2004). ${ }^{22}$ The three brain regions of interest $(n=6)$ were ground in liquid nitrogen and homogenized using an extraction solution containing $70 \mathrm{mM}$ sucrose, $210 \mathrm{mM}$ mannitol, $5 \mathrm{mM}$ Tris base, $1 \mathrm{mM}$ EDTA, $\mathrm{pH}$ 7.4. A centrifugation $\left(800 \mathrm{~g}, 10 \mathrm{~min}, 4^{\circ} \mathrm{C}\right)$ was carried out to collect a supernatant which was subjected to a second centrifugation $\left(13,000 \mathrm{~g}, 10 \mathrm{~min}, 4^{\circ} \mathrm{C}\right)$. The supernatant corresponding to cytosolic fraction was recovered and the pellet representing the mitochondrial fraction was washed and dissolved using the extraction solution. Proteins were determined according to Bradford (1976). ${ }^{23}$

\section{Biochemical determination of oxidative stress}

Protein carbonylation was assayed according to Wehr and Levine (2013), ${ }^{24}$ based on the interaction of DNPH with the carbonyl groups of oxidized proteins, giving rise to an hydrazone that absorbs at $366 \mathrm{~nm}$. Briefly, tissue homogenate was mixed with TCA $(20 \%)$ for protein precipitation and centrifuged $(5,000 \mathrm{~g}, 3 \mathrm{~min}$, $\left.4^{\circ} \mathrm{C}\right)$. Pellet was dissolved into $2 \mathrm{M} \mathrm{HCl}$ containing $\mathrm{DNPH}(10 \mathrm{mM})$ and incubated at dark for $10 \mathrm{~min}$ at room temperature. After protein precipitation and three washings with ethanol/ethyl acetate $(\mathrm{v} / \mathrm{v})$, pellet was dissolved into potassium phosphate buffer $(20 \mathrm{mM}$; $\mathrm{pH} 2.3$ ) containing $6 \mathrm{M} \mathrm{HCl}$, incubated for $15 \mathrm{~min}$ at $37^{\circ} \mathrm{C}$ and absorbance lectured against a blank. Results were calculated using the molar extinction coefficient of hydrazone $\left(\varepsilon=22,000 \mathrm{M}^{-1} \mathrm{~cm}^{-1}\right)$ and expressed as nmol carbonyl protein $/ \mathrm{mg}$ protein.

Xanthine Oxidase activity (XO, EC.1.17.3.2.) was measured according to Prajda and Weber (1975). ${ }^{25}$ The principle of this method is as follows: in the presence of xanthine, $\mathrm{XO}$ produces uric acid that absorbs at $293 \mathrm{~nm}$. The assay mixture consisted of tissue homogenate, potassium phosphate buffer $(100 \mathrm{mM}$; $\mathrm{pH} 7.4)$ and xanthine $(1 \mathrm{mM})$. After incubation for 90 min at $37^{\circ} \mathrm{C}$, the reaction was stopped by addition of $10 \% \mathrm{TCA}$, the mixture centrifuged $(10,000 \mathrm{~g}, 10 \mathrm{~min}$, $4^{\circ} \mathrm{C}$ ) and absorbance of the clear supernatant measured against a blank. Results were calculated using the molar extinction coefficient of uric acid $\left(\varepsilon=12.65 \mathrm{mM}^{-1} \mathrm{~cm}^{-1}\right)$ and expressed as $\mathrm{pmol}$ uric acid $/ \mathrm{min} / \mathrm{mg}$ protein.

Catalase activity (CAT, EC.1.11.1.6.) was evaluated by its ability to decompose $\mathrm{H}_{2} \mathrm{O}_{2}$ as described by Aebi (1984). ${ }^{26}$ Briefly, the assay mixture contained tissue homogenate into potassium phosphate buffer $50 \mathrm{mM}$ pH 7 containing $\mathrm{H}_{2} \mathrm{O}_{2}(30 \mathrm{mM})$ where $\mathrm{H}_{2} \mathrm{O}_{2}$ disappearance was followed at $240 \mathrm{~nm}$ during $3 \mathrm{~min}$. Results were calculated using the molar extinction coefficient for $\mathrm{H}_{2} \mathrm{O}_{2}\left(\varepsilon=39.4 \mathrm{M}^{-1} \mathrm{~cm}^{-1}\right)$ and expressed as $\mu \mathrm{mol} \mathrm{H}_{2} \mathrm{O}_{2}$ decomposed $/ \mathrm{min} / \mathrm{mg}$ protein.

Glutathione peroxidase activity (GPx, EC.1.11.1.9.) was monitored as previously described by Flohé and Günzler (1984). ${ }^{27}$ Activation of GPx inhibits the conversion of DTNB into TNB detectable at $412 \mathrm{~nm}$. Briefly, tissue homogenate was mixed with potassium phosphate buffer (100 mM; pH 7), EDTA (1 mM), $\mathrm{NaN}_{3}(10 \mathrm{mM})$, GSH $(4 \mathrm{mM})$ and $\mathrm{H}_{2} \mathrm{O}_{2}(5 \mathrm{mM})$. After incubation for $10 \mathrm{~min}$ at $37^{\circ} \mathrm{C}$, the reaction was stopped by addition of $5 \%$ TCA followed by centrifugation at $5,000 \mathrm{~g}, 5$ min, $4^{\circ} \mathrm{C}$ ). To supernatant, potassium phosphate buffer $(100 \mathrm{mM} ; \mathrm{pH} 7)$ and DNTB $(10 \mathrm{mM})$ were added and the optical density was read. Results were calculated using the molar extinction coefficient of TNB $\left(\varepsilon=14,150 \mathrm{M}^{-1} \mathrm{~cm}^{-1}\right)$ and expressed as nmol GSH consumed $/ \mathrm{min} / \mathrm{mg}$ protein.

Superoxide dismutase activity (SOD, EC.1.15.1.1.) was determined by a modified method of Misra and Fridovich (1972). ${ }^{28}$ By trapping superoxide anion $\left(\mathrm{O}_{2}{ }^{-}\right)$at alkaline $\mathrm{pH}$, SOD inhibits the autoxidation of epinephrine to adrenochrome, which is detectable at $480 \mathrm{~nm}$. One unit of SOD is defined as the amount of enzyme that inhibits adenochrome formation by $50 \%$. The reaction mixture contained tissue homogenate, carbonate buffer $(50 \mathrm{mM} ; \mathrm{pH} 10.2)$, bovine catalase (5 $\mathrm{U} / \mu \mathrm{L})$ and epinephrine $(5 \mathrm{mg} / \mathrm{mL})$, change in absorbance was recorded during $3 \mathrm{~min}$ and results expressed as $\mathrm{U} / \mathrm{mg}$ protein. Characterization of SOD 
isoforms was performed using $3 \mathrm{mM} \mathrm{KCN}$, which inhibits $\mathrm{Cu} / \mathrm{Zn}-\mathrm{SOD}$ and did not affect Mn-SOD.

\section{Determination of energy fueling disturbances}

$\alpha$-ketoglutarate dehydrogenase activity $(\alpha-\mathrm{KGDH}$, EC.1.2.4.2.) was determined according to Massey $(1960) .{ }^{29}$ The assay mixture contained potassium phosphate buffer (200 mM pH 7.4), $\alpha \mathrm{KG}$ (600 mM), BSA $(1 \%)$ and $\mathrm{K}_{3}\left[\mathrm{Fe}(\mathrm{CN})_{6}\right](30 \mathrm{mM})$. The reaction was initiated by addition of mitochondrial fraction and reduction of the artificial electron acceptor ferricyanide $\left(\left[\mathrm{Fe}(\mathrm{CN})_{6}\right]^{3-}\right)$ was followed against a blank at $420 \mathrm{~nm}$ for $3 \mathrm{~min}$. Results were expressed as $\mu \mathrm{mol}$ succinate formed $/ \mathrm{min} / \mathrm{mg}$ protein using the molar extinction coefficient of $\left[\mathrm{Fe}(\mathrm{CN})_{6}\right]^{3-}\left(\varepsilon=1040 \mathrm{M}^{-1} \mathrm{~cm}^{-1}\right)$.

Fumarase activity (FH, EC.4.2.1.2.) was evaluated according to Racker (1950). ${ }^{30}$ Briefly, mitochondrial fraction was added to a mixture containing potassium phosphate buffer $(50 \mathrm{mM}$; $\mathrm{pH} 7,4)$ and L-malate $(500$ $\mathrm{mM}$ ) and appearance of fumarate monitored at 240 $\mathrm{nm}$ during $10 \mathrm{~min}$. Results were expressed as nmol fumarate $/ \mathrm{min} / \mathrm{mg}$ protein using the molar extinction coefficient of fumarate $\left(\varepsilon=2440 \mathrm{M}^{-1} \mathrm{~cm}^{-1}\right)$.

$\mathrm{NADH}$ dehydrogenase activity (Electron Transport Chain ETC complex I, EC.7.1.1.2.) was determined as described by Hatefi (1978). ${ }^{31}$ The principle of this method is as follows: the amount of $\mathrm{NAD}^{+}$produced by $\mathrm{NADH}$ dehydrogenase promotes the reduction of the artificial electron acceptor $\left(\left[\mathrm{Fe}(\mathrm{CN})_{6}\right]^{3-}\right)$ that absorbs at $420 \mathrm{~nm}$. The assay mixture contained potassium phosphate buffer (50 $\mathrm{mM} \mathrm{pH} \mathrm{7.4),} \mathrm{NADH} \mathrm{(8.5} \mathrm{mM)}$ and $\mathrm{K}_{3}\left[\mathrm{Fe}(\mathrm{CN})_{6}\right](30 \mathrm{mM})$. The reaction was initiated by the addition of mitochondrial fraction and optical density recorded against a blank for 3 min. Results were expressed as nmol $\mathrm{NAD}^{+}$produced $/ \mathrm{min} / \mathrm{mg}$ protein, using the molar extinction coefficient of $[\mathrm{Fe}(\mathrm{CN})]_{6}^{3-}(\varepsilon$ $\left.=1040 \mathrm{M}^{-1} \mathrm{~cm}^{-1}\right)$.

Succinate dehydrogenase activity (SDH, ETC complex II, EC.1.3.5.1.) was assayed according to King (1967). ${ }^{32}$ The method involves the oxidation of succinic acid by $\left[\mathrm{Fe}(\mathrm{CN})_{6}\right]^{3-}$. The assay mixture contained sodium phosphate buffer (200 mM; pH 7.8), succinic acid $(600 \mathrm{mM})$, BSA $(1 \%)$ and $\mathrm{K}_{3}\left[\mathrm{Fe}(\mathrm{CN})_{6}\right](30 \mathrm{mM})$. The reaction was initiated by the addition of mitochondrial fraction and absorbance followed against a blank at $420 \mathrm{~nm}$ during $3 \mathrm{~min}$. Results were expressed as $\mu \mathrm{mol}$ succinate oxidized $/ \mathrm{min} / \mathrm{mg}$ protein, using the molar extinction coefficient of $\left[\mathrm{Fe}(\mathrm{CN})_{6}\right]^{3-}\left(\varepsilon=1040 \mathrm{M}^{-1} \mathrm{~cm}^{-1}\right)$. Glutamate dehydrogenase activity (GDH, EC.1.4.1.3.) was measured according to Kim et al. (2017) with minor modification. ${ }^{33}$ Mitochondrial fraction was added to an assay mixture containing $50 \mathrm{mM}$ sodium phosphate buffer ( $\mathrm{pH}$ 7.4), $1 \mathrm{mM}$ ADP and $0.1 \mathrm{mM} \mathrm{NAD}^{+}$. The reaction was initiated by adding $10 \mathrm{mM}$ glutamate and the reduction of $\mathrm{NAD}^{+}$was followed at $340 \mathrm{~nm}$ for 10 min. Results were expressed as nmol NADH produced/ $\mathrm{min} / \mathrm{mg}$ protein, using the molar extinction coefficient of NADH $\left(\varepsilon=6.22 \mathrm{mM}^{-1} \mathrm{~cm}^{-1}\right)$.

Glutamine synthetase activity (GS, EC.6.3.1.2.) was estimated as described by Min et al. (1997). ${ }^{34}$ This method is based on the ability of GS to replace glutamine's ammonia by hydroxylamine, thus forming $\gamma$-glutamylhydroxamate $(\gamma-\mathrm{GH}) . \quad B$ riefly, tissue homogenate was blended with an assay mixture containing $50 \mathrm{mM}$ imidazole buffer ( $\mathrm{pH}$ 6.8), 25 $\mathrm{mM} \mathrm{NaAsO}, 0.16 \mathrm{mM}$ ADP, $50 \mathrm{mM}$ Gln, $2.25 \mathrm{mM}$ $\mathrm{MnCl}_{2}$ and $25 \mathrm{mM} \mathrm{NH}_{2} \mathrm{OH}$. After incubation for 30 min at $37^{\circ} \mathrm{C}$, the reaction was terminated by adding a stop solution containing $2.42 \% \mathrm{FeCl}_{3}, 1.45 \%$ TCA and $1.82 \% \mathrm{HCl}$. Insoluble material was removed by centrifugation $\left(1,000 \mathrm{~g}, 3 \mathrm{~min}, 4^{\circ} \mathrm{C}\right)$ and absorbance of the supernatant measured at $540 \mathrm{~nm}$ against a blank. Results were expressed as nmol $\gamma$-GH formed $/ \mathrm{min} / \mathrm{mg}$ protein, using the molar extinction coefficient of $\gamma-\mathrm{GH}$ $\mathrm{FeCl}_{3}$ complex $\left(\varepsilon=850 \mathrm{M}^{-1} \mathrm{~cm}^{-1}\right)$.

Glyceraldehyde-3-phosphate dehydrogenase activity (GAPDH, EC.1.2.1.12.) was measured following a modified method of Krebs (1955).$^{35}$ Cytosolic fraction was mixed with sodium phosphate buffer $150 \mathrm{mM} \mathrm{pH}$ 8 containing $\mathrm{NaAsO}_{2}(30 \mathrm{mM}), \mathrm{NAD}^{+}(7.5 \mathrm{mM})$ and GA3P $(7.5 \mathrm{mM})$ and reduction of $\mathrm{NAD}^{+}$to NADH was monitored at $340 \mathrm{~nm}$ for $5 \mathrm{~min}$. Results were expressed as $\mathrm{nmol} \mathrm{NADH} / \mathrm{min} / \mathrm{mg}$ protein, using the molar extinction coefficient of NADH $\left(\varepsilon=6.22 \mathrm{mM}^{-1} \mathrm{~cm}^{-1}\right)$.

\section{Mitochondrial survival}

Mitochondrial viability was measured according to Liu $e t$ al. (1997). ${ }^{36}$ The assay is based on the reduction of MTT by dehydrogenases of functionally intact mitochondria. Briefly mitochondrial fraction was incubated with 20 $\mu \mathrm{l} \mathrm{MTT}(0.1 \mathrm{mg} / \mathrm{mL})$ for $60 \mathrm{~min}$ at $37^{\circ} \mathrm{C}$. Then, the obtained blue formazan crystals were solubilized in isopropanol and the optical density followed at 578 $\mathrm{nm}$. Results were expressed as nmol formazan/min/ $\mathrm{mg}$ protein using the molar extinction coefficient of formazan $\left(\varepsilon=16,900 \mathrm{M}^{-1} \mathrm{~cm}^{-1}\right)$.

\section{Measurement of brain infarct size}

Infarct size was determined using the TTC staining method of Bederson et al. (1986) $)^{37}$ with slight modifications. Brains were frozen for $30 \mathrm{~min}$ at $-80^{\circ} \mathrm{C}$ and sliced into seven coronal sections of 2 - $\mathrm{mm}$ thick. Each slice was immersed in TTC (1\%) for $30 \mathrm{~min}$ at $37^{\circ} \mathrm{C}$ and then fixed overnight in buffered formaldehyde 
$(10 \%)$. The fixed brain sections were photographed using a Canon EOS 450D camera and analyzed using Image J1.52a software. The percentage of infarct size was calculated as the ratio of unstained areas and total red colored area for each section.

\section{Determination of intracellular mediators}

Hydrogen peroxide $\left(\mathrm{H}_{2} \mathrm{O}_{2}\right)$ was determined using a commercially available kit from Biomaghreb according to Trinder (1969). ${ }^{38}$ Briefly, in the presence of peroxidase, $\mathrm{H}_{2} \mathrm{O}_{2}$ reacts with 4-amino-antipyrine and phenol to give a red colored quinoeimine that absorbs at $505 \mathrm{~nm}$. Results were calculated using a standard curve of $\mathrm{H}_{2} \mathrm{O}_{2}$ $(0-1250 \mathrm{nmol} / \mathrm{mL})$ and expressed as $\mathrm{nmol} \mathrm{H}_{2} \mathrm{O}_{2} / \mathrm{mg}$ protein.

Free iron was estimated according to Leardi et al. $(1998)^{39}$ using a commercially available kit from Biomaghreb (Tunisia). At acidic $\mathrm{pH}$, all ferric iron $\left(\mathrm{Fe}^{3+}\right)$ released from ferritins is reduced by ascorbic acid into ferrous iron $\left(\mathrm{Fe}^{2+}\right)$, which constitutes with ferrozine a purple colorful complex measurable at $560 \mathrm{~nm}$. Results were calculated using a standard curve of iron (0-8.95 nmol/ $\mathrm{mL}$ ) and expressed as nmol free iron/mg protein.

Ionized calcium $\left(\mathrm{Ca}^{2+}\right)$ was measured using a commercially available kit from Biomaghreb according to Stern and Lewis (1957). ${ }^{40}$ At basic pH, $\mathrm{Ca}^{2+}$ constitutes with cresolphtalein a purple colorful complex measurable at $570 \mathrm{~nm}$. Results were calculated using a standard curve of calcium $(0-312.5 \mathrm{nmol} / \mathrm{mL})$ and expressed as nmol $\mathrm{Ca}^{2+} / \mathrm{mg}$ protein.

\section{Statistical analysis}

Statistical analysis was performed using IBM SPSS Statistics v.23.0 software (Armonk, NY, USA). Results were expressed as mean \pm standard error of the mean (SEM). Statistical difference between group means was assessed by one-way analysis of variance (one-way ANOVA) followed by Student's $t$-test. Probability value $p$ less than 0.05 was considered statistically significant.

\section{RESULTS}

\section{Effect of GSE and ORL on I/R-induced infarct size}

We first validated the $\mathrm{I} / \mathrm{R}$ protocol by quantifying infarct size (Figure 1). In control non $\mathrm{I} / \mathrm{R}$ animals no obvious damage was detected. Brain sections from rats submitted to $\mathrm{I} / \mathrm{R}$ revealed an infarct size of 15.8 $\pm 0.7 \%$ predominately located in prefrontal cortex and hippocampus. Pretreatment with GSE alone induced a reduction of brain infarction by $56.9 \%(p<0.001)$, while the preventive treatment with ORL alone generated a decrease by $30.0 \%(p<0.05)$. The best neuroprotection was obtained when associating the two drugs $(-73.7 \%$, $p<0.001)$.

\section{Effect of GSE and ORL on I/R-induced oxidative stress}

We determined oxidative damage by quantifying protein carbonylation (Figure 2 ) which was significantly increased into cortex $(+22.7 \%, \quad p<0.05)$ and hippocampus $(+32.1 \%, p<0.001)$ and to a lesser extent within cerebellum $(+17.6 \%)$. Pretreatment with GSE remarkably alleviated protein carbonylation, which was not further improved upon ORL addition.

Moreover, we looked at the activity of the prooxidant enzyme XO (Figure 3). I/R increased XO activity in cortex $(+31.5 \%, p<0.05)$, hippocampus $(+59.1 \%$, $p<0.05)$ and cerebellum $(+25.7 \%)$; GSE and ORL per se corrected XO activity to near control level whereas drugs combination did no exert any improvement.

We further sought to evaluate the activity of the antioxidant enzymes CAT (Figure 4), GPx (Figure 5) and SOD (Figure 6). Concerning CAT activity I/R affected significantly CAT activity within hippocampus $(-26.3 \%, p<0.001)$ and slightly increased it within cortex $(+14.8 \%, p<0.05)$ and cerebellum $(+19.0 \%, p<0.001)$. $\mathrm{I} / \mathrm{R}$ affected GPx activity only within hippocampus $(-40.5 \%, p<0.05)$ which was corrected upon GSE
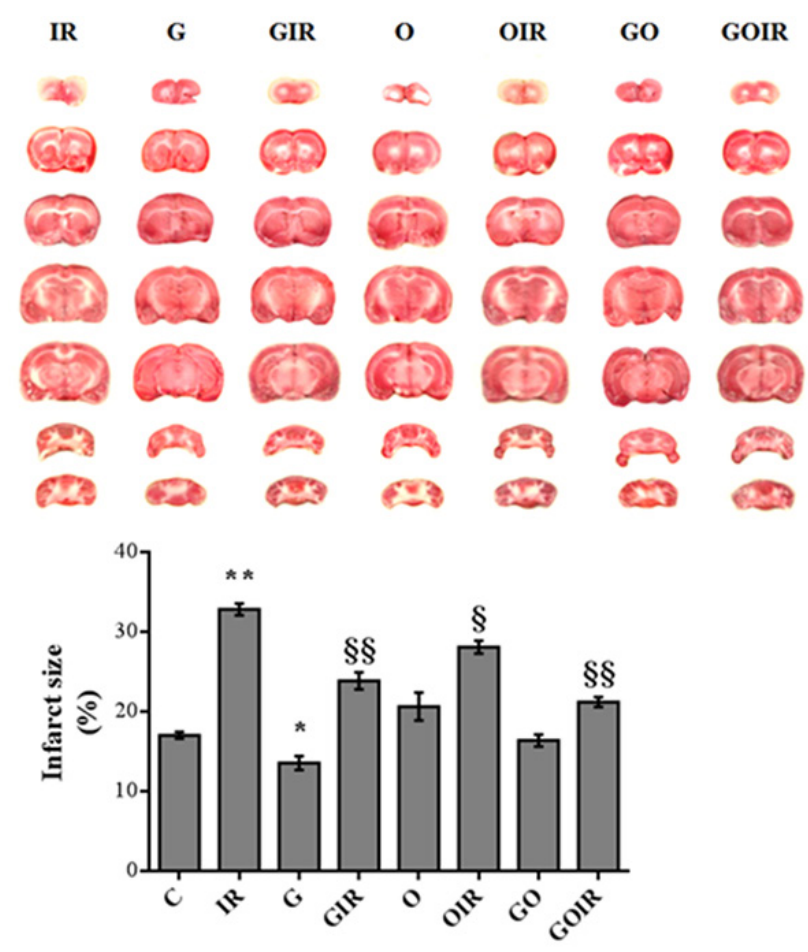

Figure 1: Effect of GSE and ORL on I/R-induced cerebral infarct size. * $p<0.05$ for $G$ versus $C$, ** $p<0.001$ for IR versus C, $\S p<0.05$ for OIR versus IR, $\S \S p<0.001$ for GIR or GOIR versus IR. 
treatment but not with ORL. I/R also affected total SOD activity especially within hippocampus $(-27.5 \%$, $p<0.001)$, cortex $(-16.2 \%, p<0.001)$ and to a lesser extent within cerebellum $(-12.8 \%, p<0.05)$. The $\mathrm{Mn}$ isoform was the main affected within hippocampus, cortex and cerebellum by $-32.3 \%,-25.5 \%,-16.3 \%$

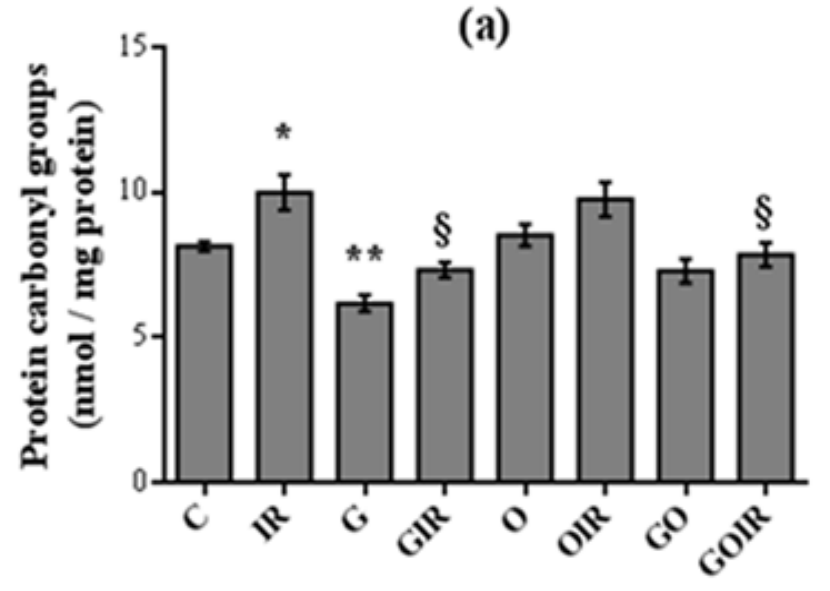

(b)

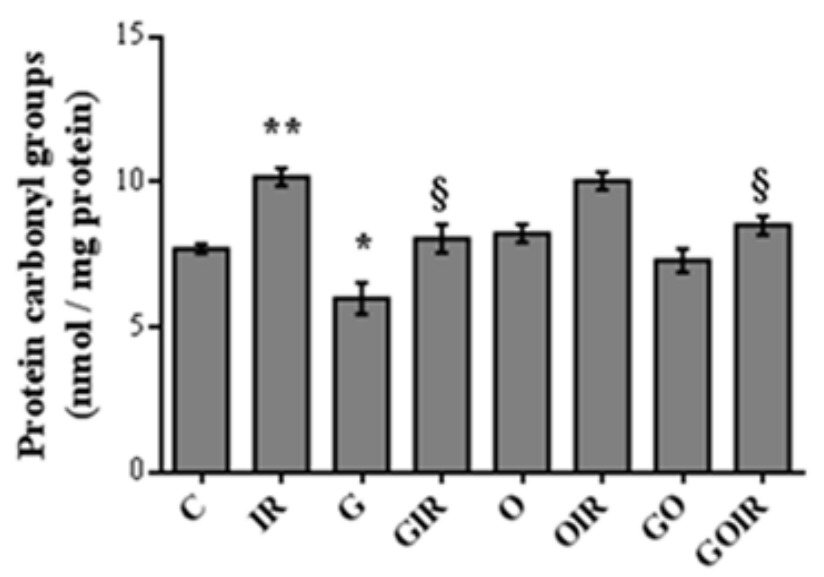

(c)

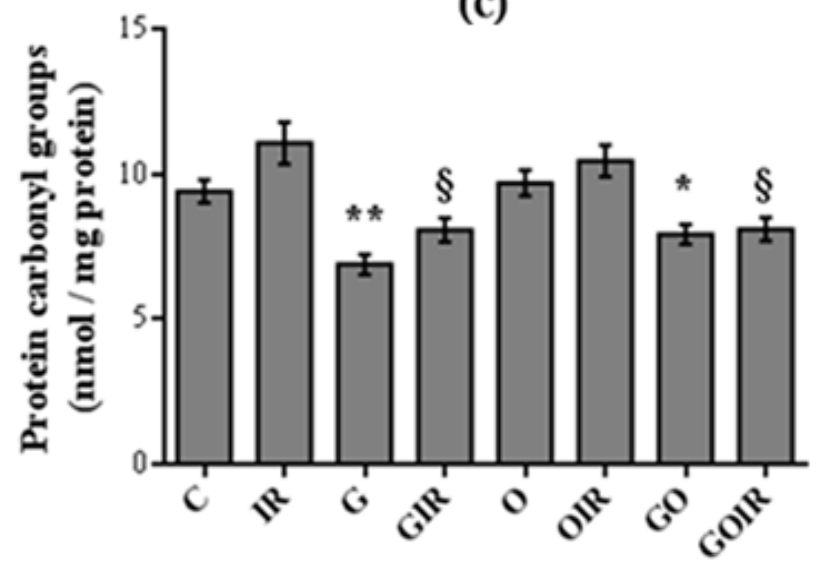

Figure 2: Effect of GSE and ORL on protein carbonylation in (a) cortex, (b) hippocampus and(c) cerebellum. ${ }^{*}<<0.05$ for IR, $\mathrm{G}$ or $\mathrm{GO}$ versus $\mathrm{C}$, ${ }^{* *} p<0.001$ for IR or $\mathrm{G}$ versus $\mathrm{C}, \S p<0.05$ for GIR or GOIR versus IR. $(p<0.05)$ respectively whereas the $\mathrm{Cu} / \mathrm{Zn}$ isoform was affected only in hippocampus by $(-24.3 \% p<0.05)$. GSE mainly improved the $\mathrm{Mn}$ isoform in all compartments whereas ORL adjunction rather improved $\mathrm{Cu} / \mathrm{Zn}$ isoform and the best protection was obtained in the presence of both drugs.

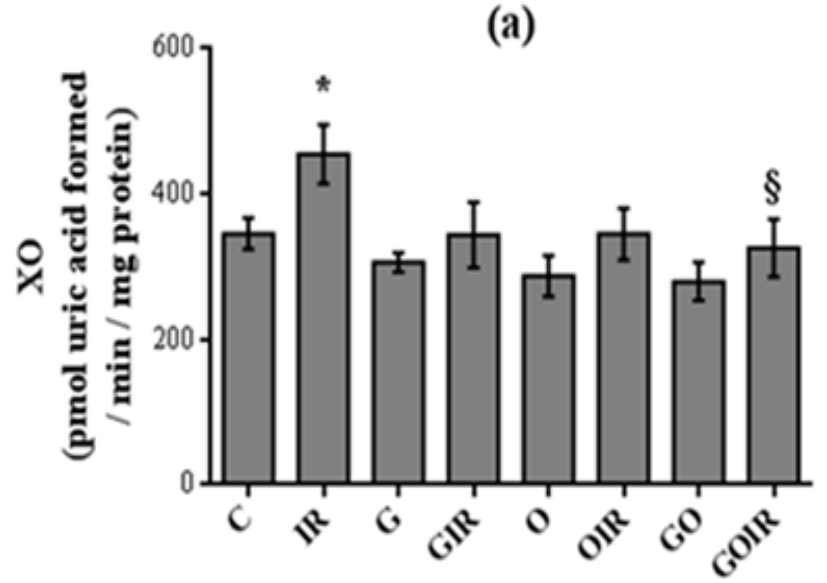

(b)

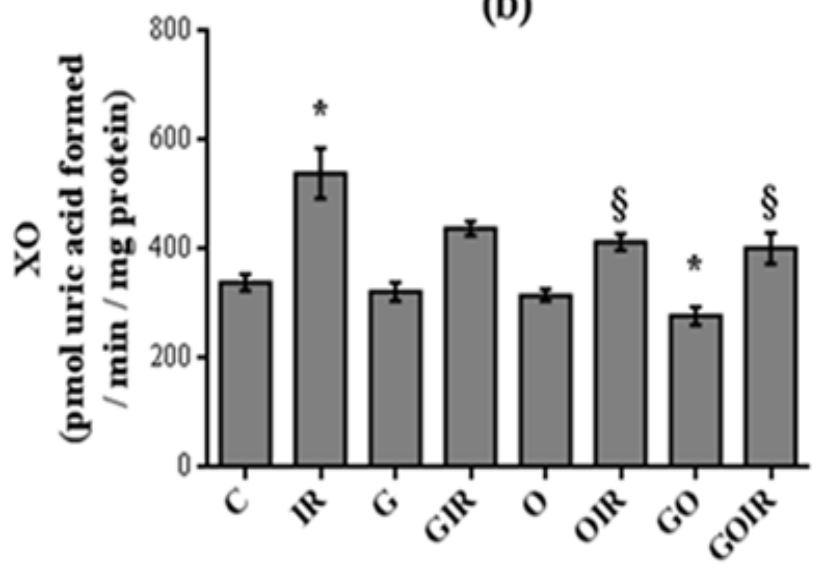

(c)

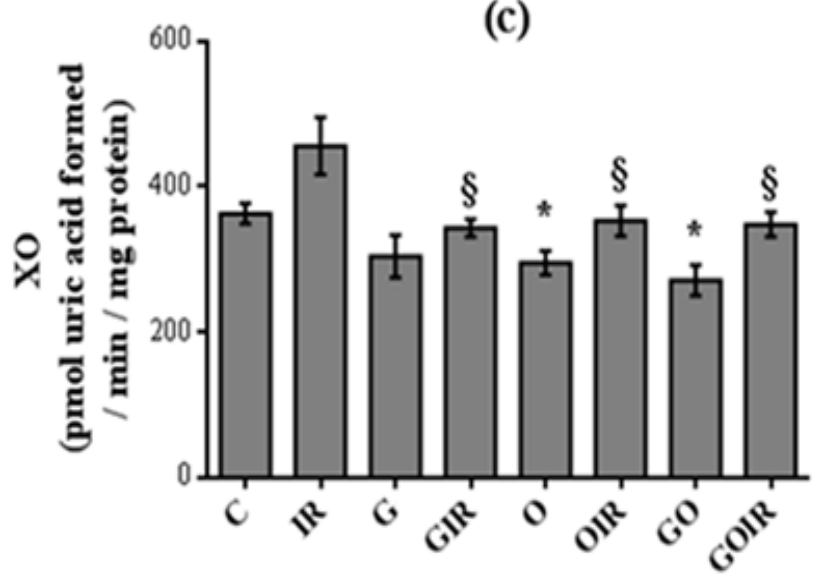

Figure 3: Effect of GSE and ORL on XO activity in (a) cortex, (b) hippocampus and (c) cerebellum. ${ }^{*} p<0.05$ for IR, $O$ or GO versus $\mathrm{C}, \S p<0.05$ for GIR, OIR or GOIR versus IR. 
Effect of GSE and ORL on I/R-induced brain energy failure

We first asked whether I/R as well as GSE and ORL were able to affect the TCA cycle through modulation of $\alpha-\mathrm{KGDH}$ (Figure 7) and fumarase activities (Figure 8). I/R reduced drastically $\alpha-\mathrm{KGDH}$ activity within hippocampus $(-37.4 \%, p<0.001)$ and cortex $(-30.9 \%, p<0.001)$ but had no significant effect within cerebellum $(-9.6 \%)$. I/ $\mathrm{R}$ also affected fumarase activity mainly within cortex $(-17.9 \%)$, hippocampus (a)

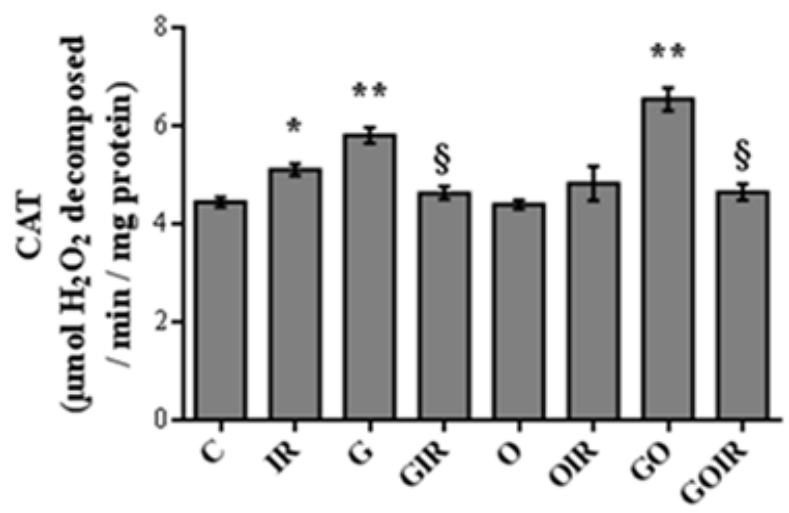

(b)

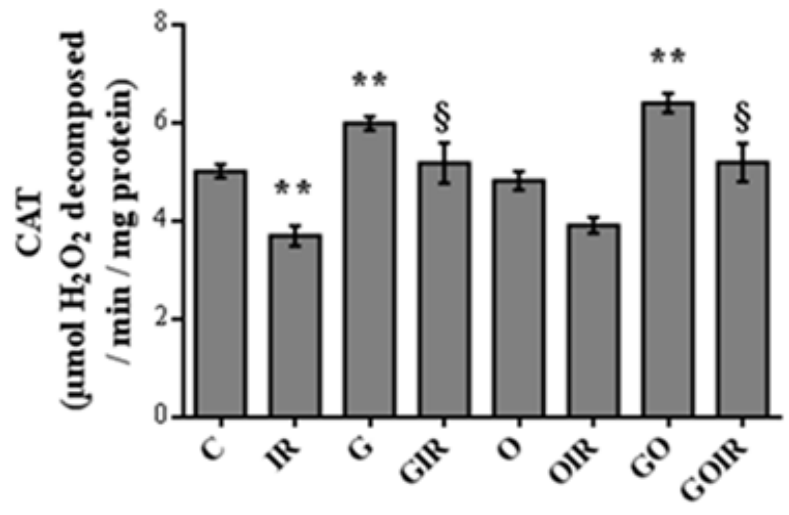

(c)

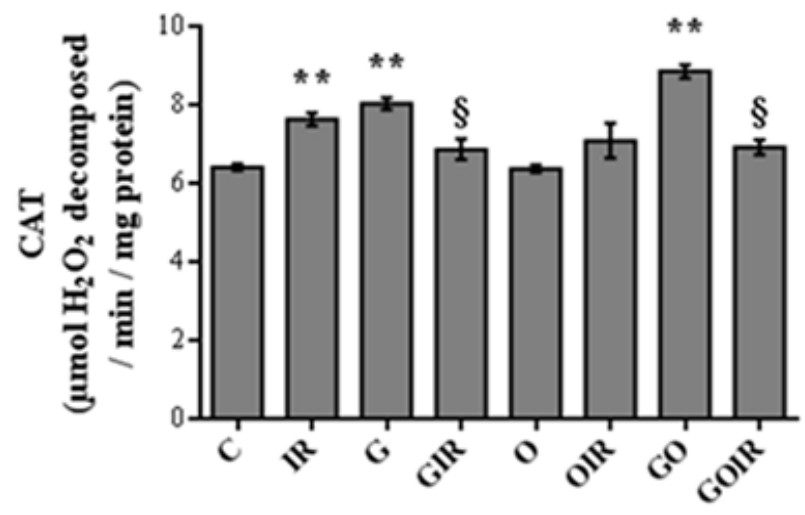

Figure 4: Effect of GSE and ORL on CAT activity in (a) cortex, (b) hippocampus and (c) cerebellum. ${ }^{*} p<0.05$ for IR versus $C$, ** $p<0.001$ for IR, G or GO versus $C, \S p<0.05$ for GIR or GOIR versus IR. (a)

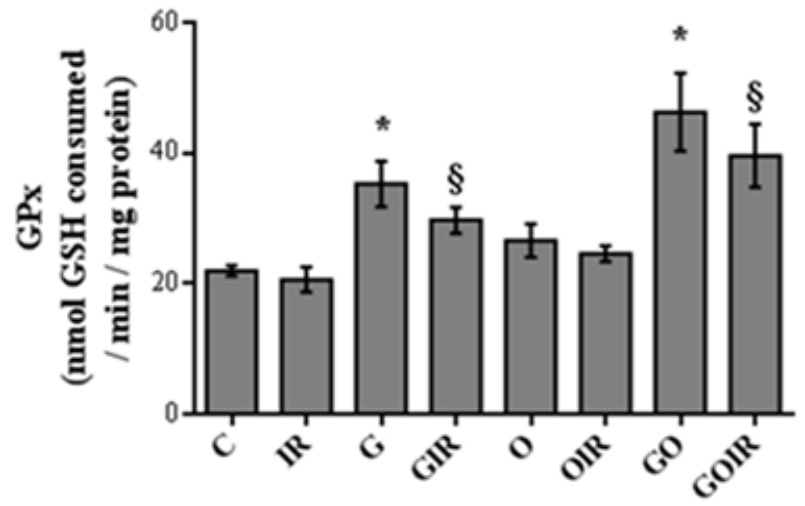

(b)

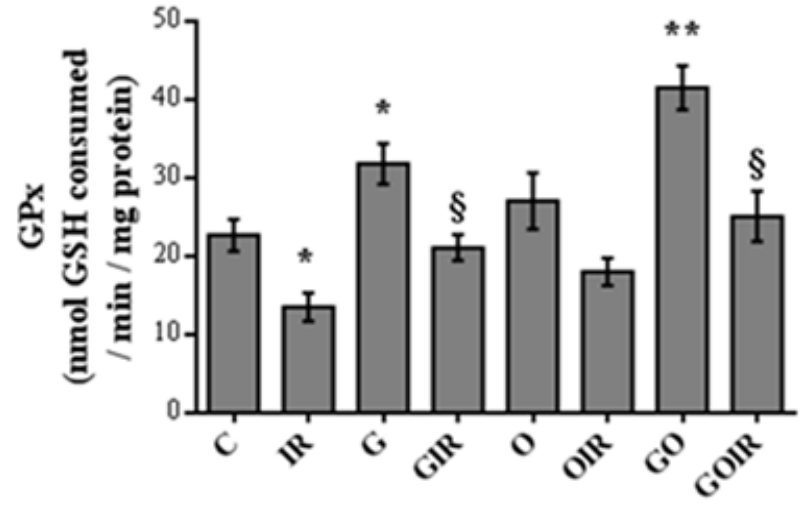

(c)

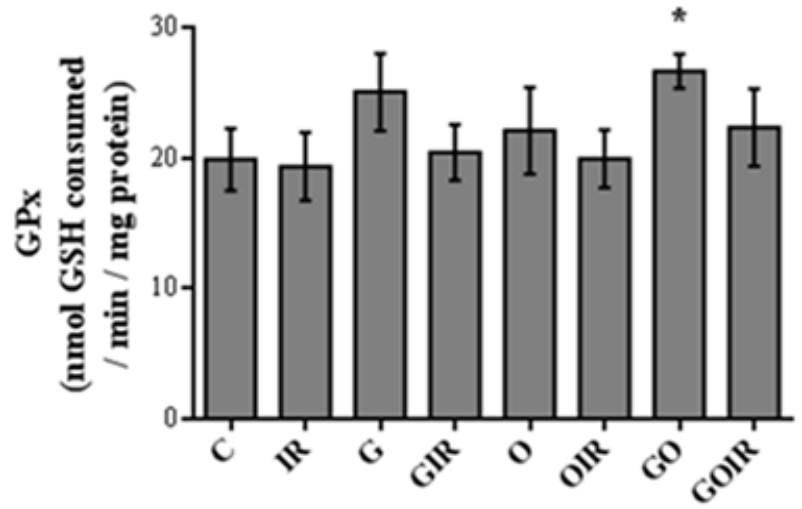

Figure 5: Effect of GSE and ORL on GPx activity in (a) cortex, (b) hippocampus and (c) cerebellum. ${ }^{*} p<0.05$ for IR, G or GO versus $C,{ }^{* *} p<0.001$ for $G 0$ versus $C, \S p<0.05$ for $\mathrm{GIR}$ or GOIR versus IR. 
$(-18.8 \%, p<0.05)$ and to a lesser extent within cerebellum $(-9.2 \%)$. Pretreatment with ORL corrected both $\alpha-K G D H$ and fumarase activities more efficiently than GSE alone and the best protection was obtained

(a)

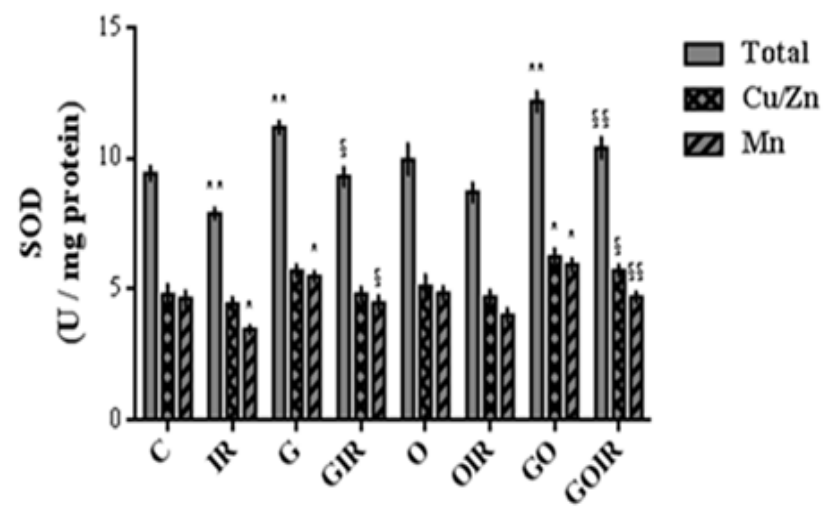

(b)

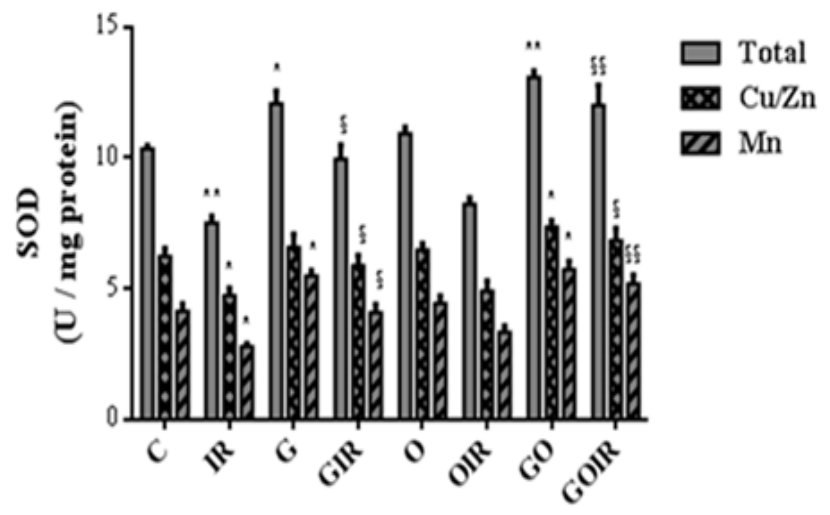

(c)

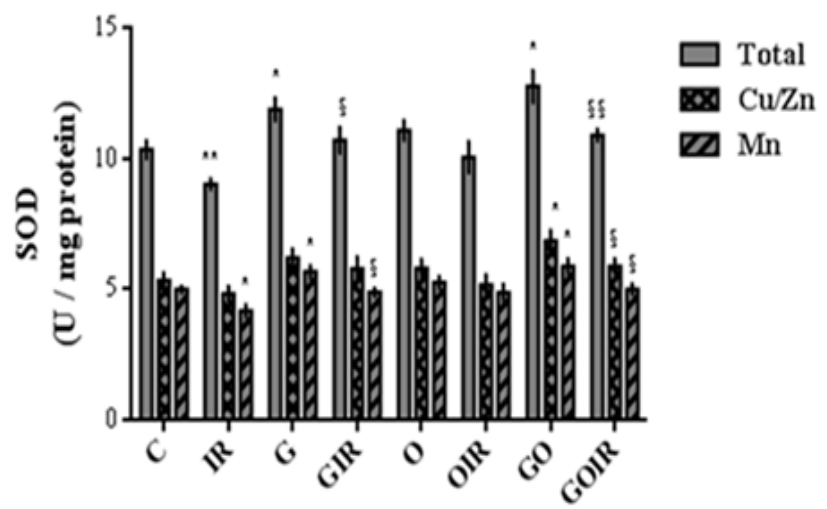

Figure 6: Effect of GSE and ORL on SOD activity in (a) cortex, (b) hippocampus and (c) cerebellum. ${ }^{*} p<0.05$ for IR, G or GO versus $\mathrm{C},{ }^{* *} p<0.001$ for IR, $\mathrm{G}$ or $\mathrm{GO}$ versus $\mathrm{C}, \S p<0.05$ for GIR or GOIR versus IR, $\S \S p<0.001$ for GOIR versus IR. in the presence of both drugs. Overally data showed that $\mathrm{I} / \mathrm{R}$ mainly affected the cortex and hippocampus compartments and that GSE and ORL, especially when combined afforded the best protection. (a)

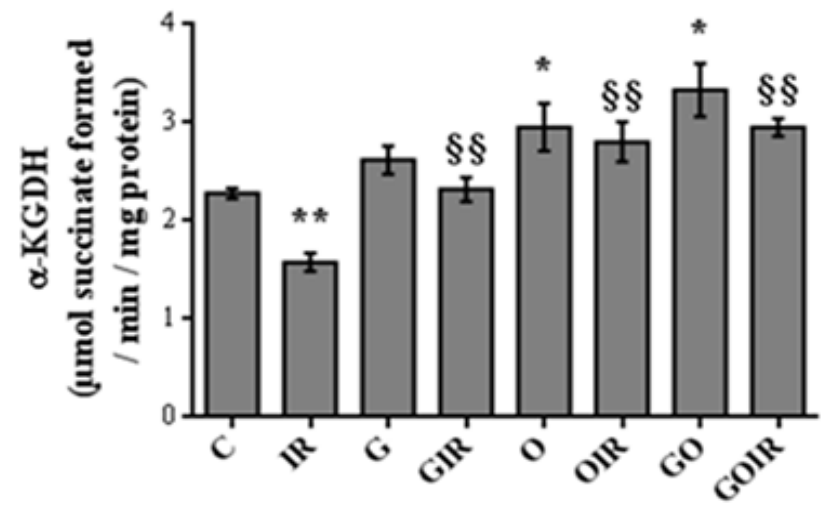

(b)

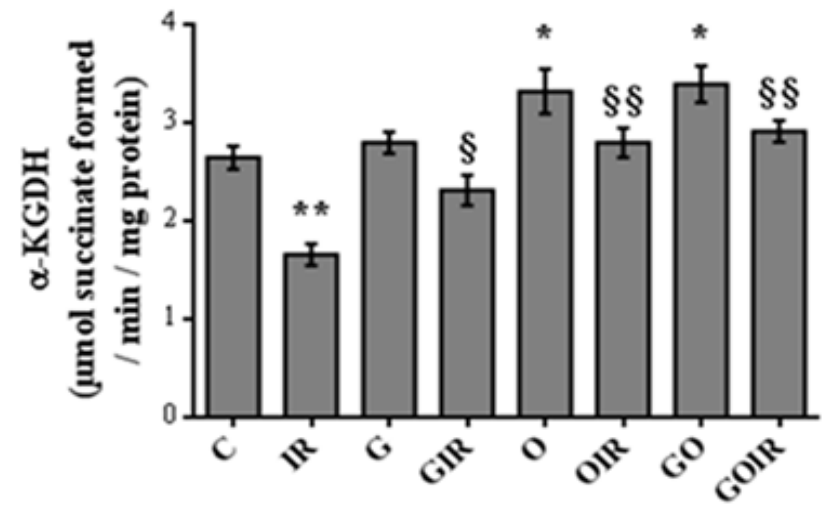

(c)

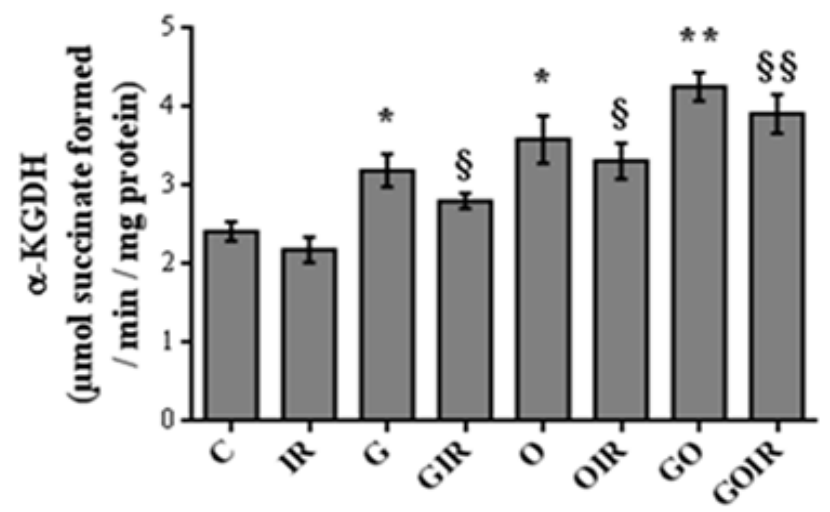

Figure 7: Effect of GSE and ORL on a-KGDH activity in (a) cortex, (b) hippocampus and (c) cerebellum. ${ }^{*} p<0.05$ for $\mathrm{G}, \mathrm{O}$ or $\mathrm{GO}$ versus $\mathrm{C},{ }^{* *} p<0.001$ for IR or $\mathrm{GO}$ versus $\mathrm{C}, \S p<0.05$ for GIR or OIR versus IR, $\S \S p<0.001$ for GIR, OIR or GOIR versus 
We also looked at the effect of $\mathrm{I} / \mathrm{R}$ on mitochondrial oxidative phosphorylation (Oxphos) complexes via evaluating the activity of ETC complex I (Figure 9) and complex II (Figure 10) activities. I/R drastically decreased complex I activity within hippocampus $(-40.6 \%, p<0.001)$ and cortex $(-18.0 \%, p<0.001)$

(a)

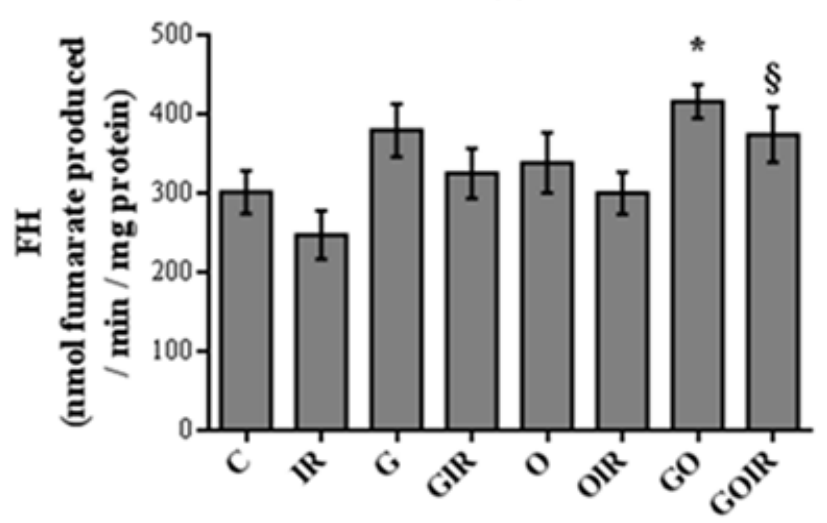

(b)

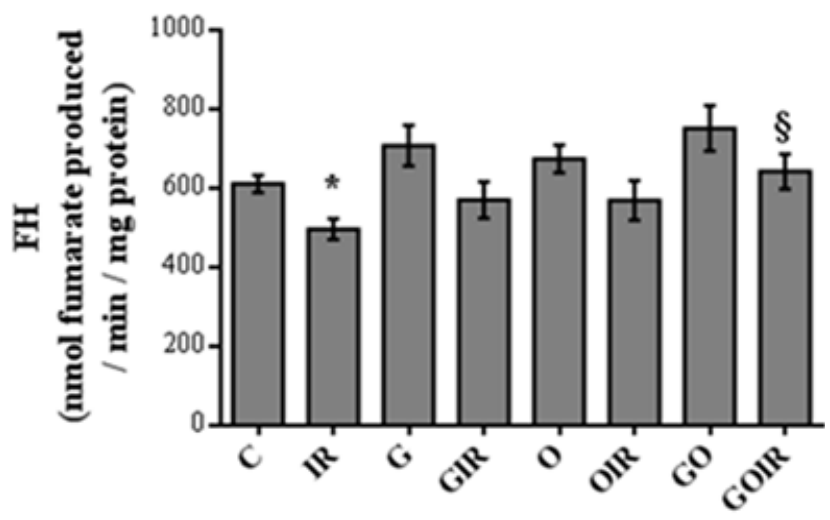

(c)

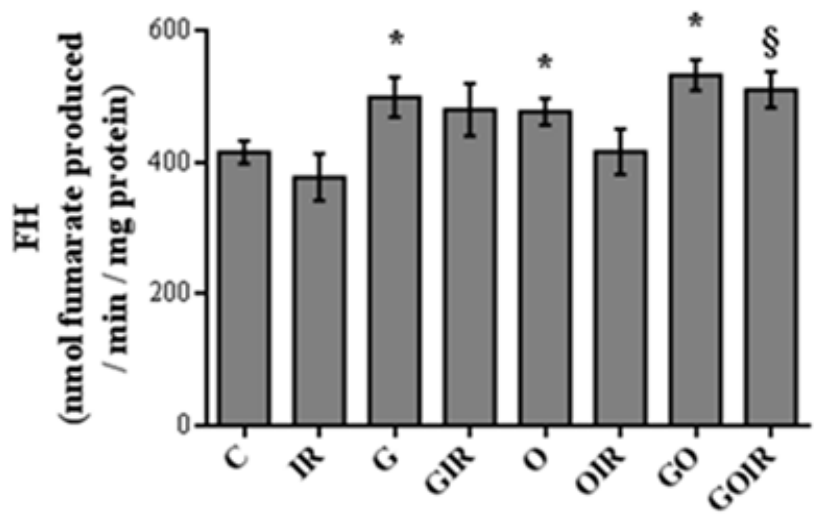

Figure 8: Effect of GSE and ORL on fumarase activity in (a) cortex, (b) hippocampus and (c) cerebellum. ${ }^{*} p<0.05$ for IR, G, $\mathrm{O}$ or $\mathrm{GO}$ versus $\mathrm{C}, \S p<0.05$ for GOIR versus IR. with no significant effect within cerebellum $(-4.7 \%)$. Similarly I/R highly decreased complex II activity within hippocampus $(-49.8 \%, p<0.001)$ and cortex $(-35.6 \%, p<0.001)$ but more modestly within cerebellum $(-15.6 \%)$. Pretreatment with ORL per se corrected the

(a)

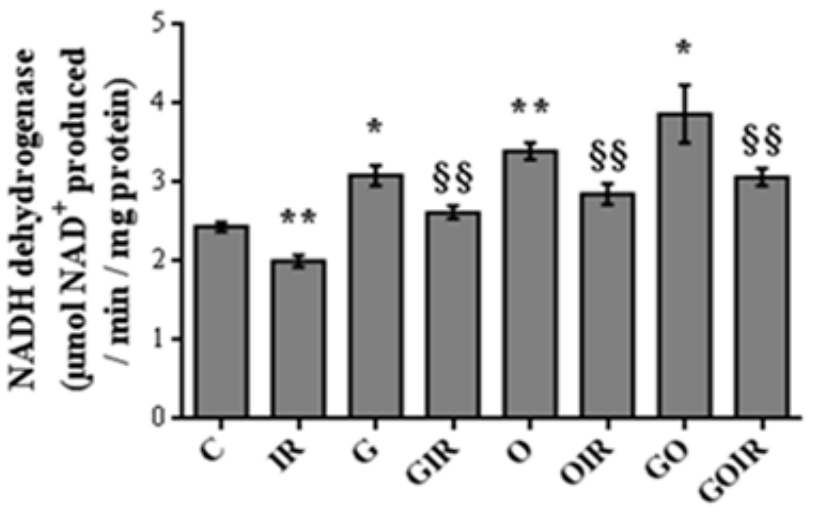

(b)

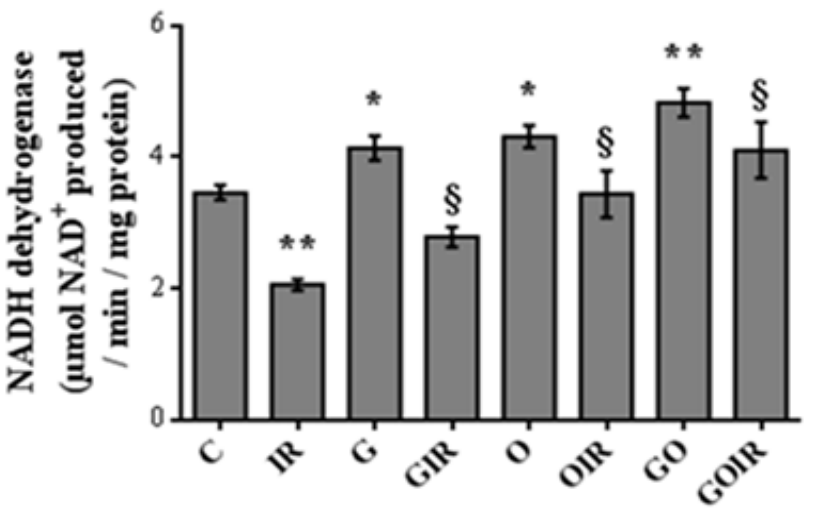

(c)

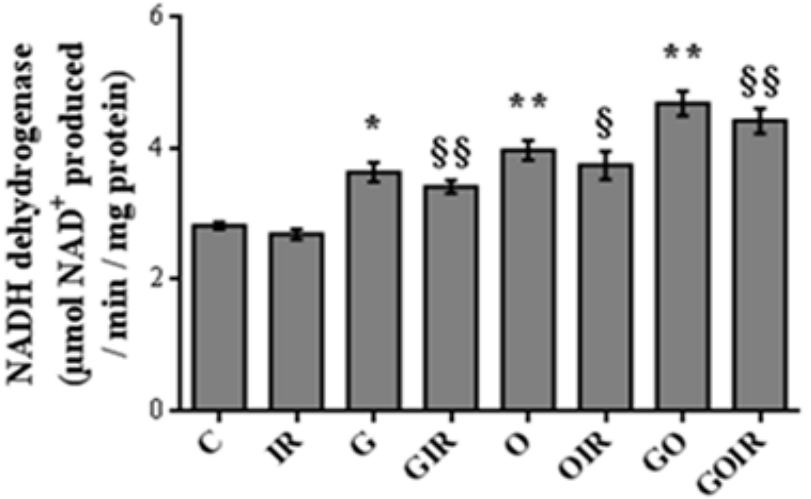

Figure 9: Effect of GSE and ORL on ETC complex I activity in (a) cortex, (b) hippocampus and (c) cerebellum. ${ }^{*} \mathrm{p}<0.05$ for $\mathrm{G}, \mathrm{O}$ or $\mathrm{GO}$ versus $\mathrm{C},{ }^{* *} p<0.001$ for IR, $\mathrm{O}$ or GO versus $\mathrm{C}, \S$ $p<0.05$ for GIR, OIR or GOIR versus IR, $\S \S p<0.001$ for GIR, OIR or GOIR versus IR. 
alteration on both ETC complexes more efficiently than GSE alone and the best protection was obtained when combining the two drugs.

We also analyzed excitotoxicity through evaluating the activity of GDH (Figure 11) and GS (Figure
12) activities which are major players of glutamate metabolism. Data show that I/R dropped drastically GDH activity within hippocampus $(-45.8 \%, p<0.001)$ and cortex $(-24.2 \%, p<0.05)$ and to a lesser extent yet not significant within cerebellum $(-10.7 \%)$. Surprisingly (a)

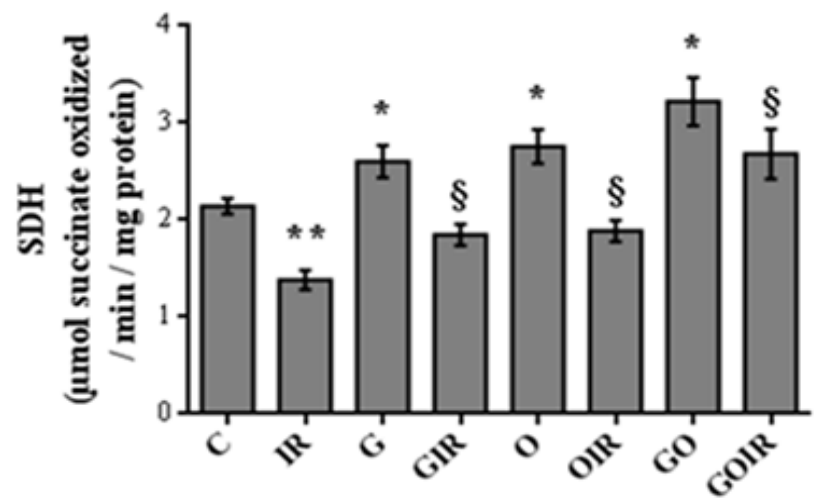

(b)

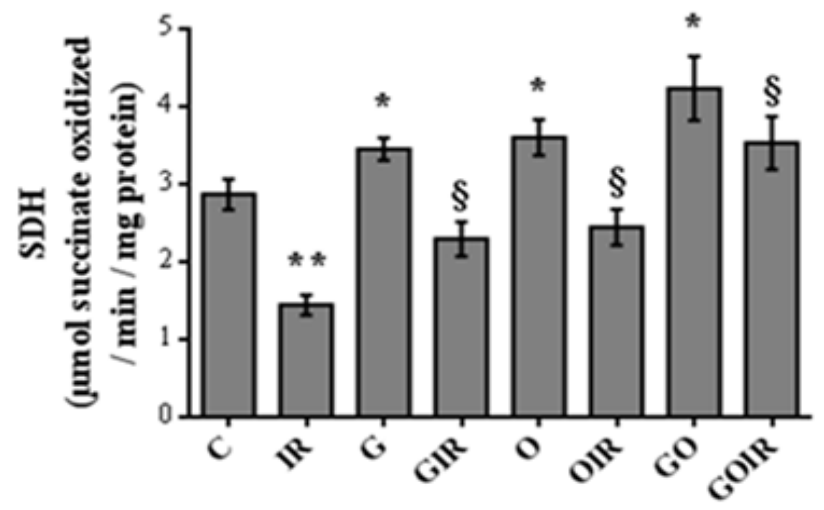

(c)

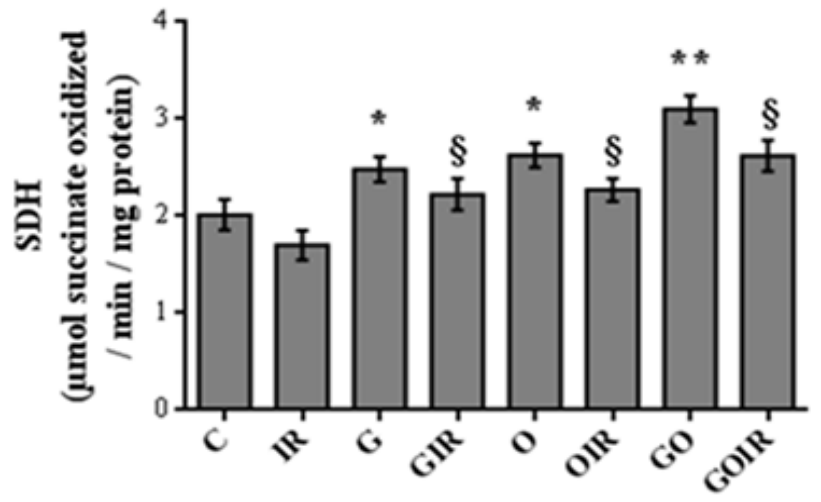

Figure 10: Effect of GSE and ORL on ETC complex II activity in (a) cortex, (b) hippocampus and (c) cerebellum. ${ }^{*} \mathrm{p}<0.05$ for $\mathrm{G}, \mathrm{O}$ or $\mathrm{GO}$ versus $\mathrm{C},{ }^{* *} \mathrm{p}<0.001$ for IR or $\mathrm{GO}$ versus $\mathrm{C}, \S$ $\mathrm{p}<0.05$ for GIR, OIR or GOIR versus IR. (a)

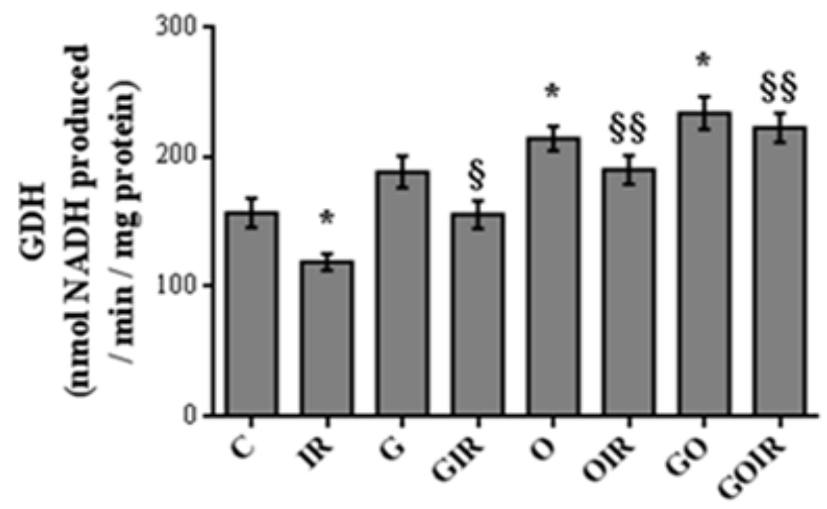

(b)

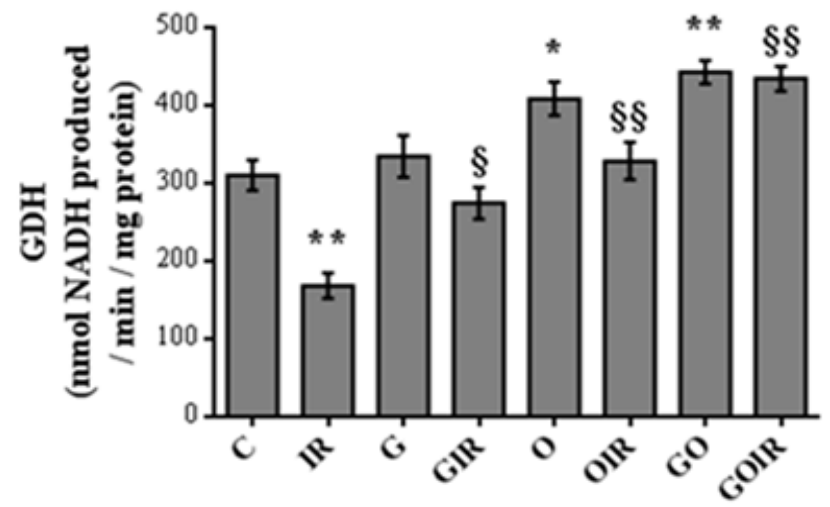

(c)

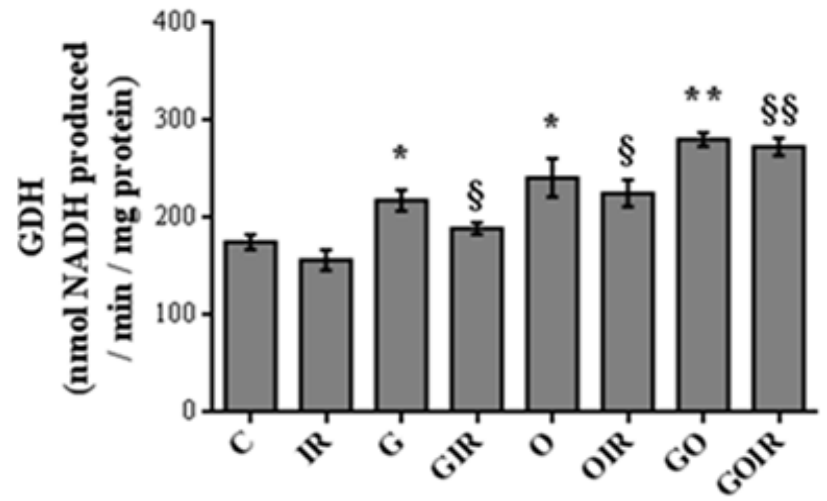

Figure 11: Effect of GSE and ORL on GDH activity in (a) cortex, (b) hippocampus and (c) cerebellum. ${ }^{*} \mathrm{p}<0.05$ for IR, G, $O$ or $\mathrm{GO}$ versus $\mathrm{C},{ }^{* *} p<0.001$ for IR or $\mathrm{GO}$ versus $\mathrm{C}, \S p<0.05$ for GIR or OIR versus IR, $\S \S p<0.001$ for OIR or GOIR versus IR. 
I/R slightly but significantly increased GS activity within hippocampus $(+18.3 \%, p<0.001)$ and cortex $(+10.8 \%)$ and to a non-significant lesser extent within cerebellum $(+7.8 \%)$. Pretreatment with ORL alone corrected the alterations in GDH and GS activities more efficiently

\section{(a)}

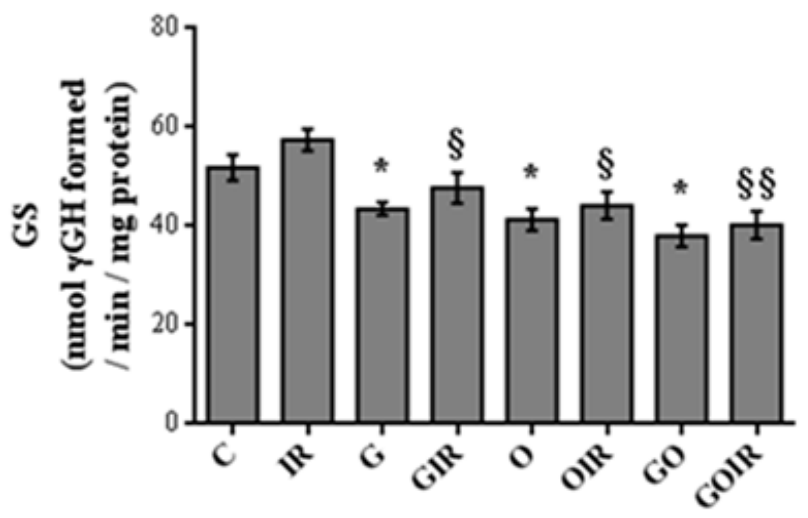

(b)

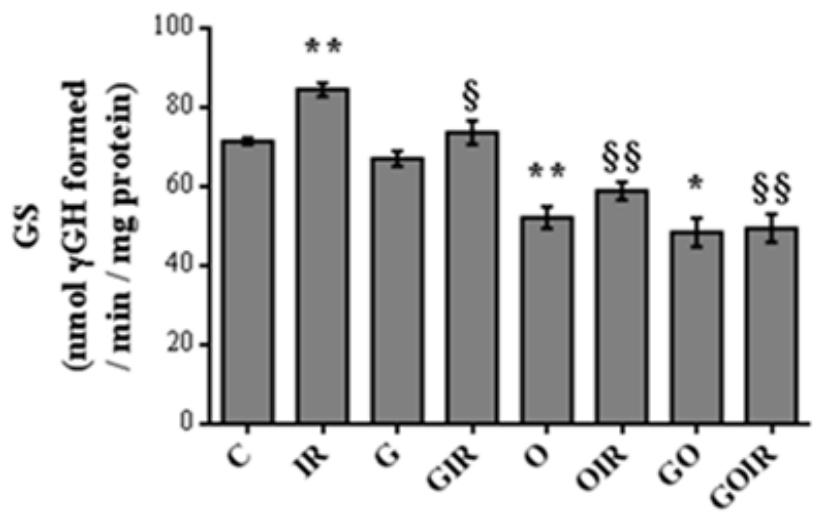

(c)

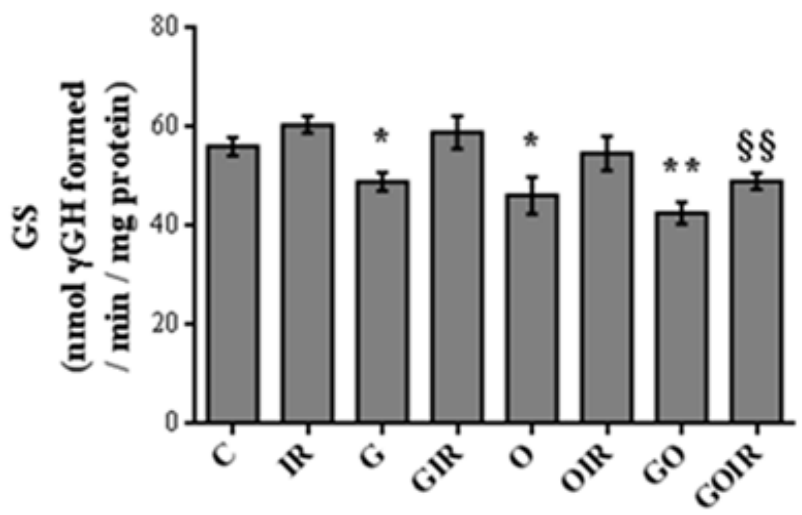

Figure 12: Effect of GSE and ORL on GS activity in (a) cortex, (b) hippocampus and (c) cerebellum. ${ }^{*} p<0.05$ for $\mathrm{G}, 0$ or $\mathrm{GO}$ versus $C$, ** $p<0.001$ for IR, 0 or $\mathrm{GO}$ versus $C, \S p<0.05$ for GIR or OIR versus IR, $\S \S p<0.001$ for OIR or GOIR versus IR. than GSE alone and the best protection was obtained when associating the two drugs.

We also investigated GAPDH activity, which is not merely a glycolytic enzyme yet involved in apoptosis pathway (Figure 13). I/R drastically increased GAPDH activity within hippocampus $(+132.0 \%, p<0.05)$ and cortex $(+57.8 \%, p<0.05)$ but had no significant effect within cerebellum $(+15.4 \%)$. Treatment with GSE and ORL per se corrected the I/R-induced alteration in GAPDH activity and a slight improvement was obtained when associating both drugs.

\section{Effect of GSE and ORL on I/R-induced mitochondrial survival}

To confirm all previous data on mitochondria enzymes involved in energy production, we further asked whether $\mathrm{I} / \mathrm{R}$ affected the overall mitochondria survival (Figure 14). I/R dropped severely mitochondrial viability within hippocampus $(-32.5 \%, p<0.05)$ and cortex $(-26.0 \%$, $p<0.05)$ and moderately within cerebellum $(-14.9 \%)$. GSE per se partly corrected I/R-induced disturbances while ORL per se was less efficient and the best protection was obtained in the presence of both drugs.

\section{Effect of GSE and ORL on V/R-induced intracellular mediators}

We further asked whether I/R affected the intracellular mediators as $\mathrm{H}_{2} \mathrm{O}_{2}$, free iron and calcium into the three brain compartments (Table 1). I/R significantly increased $\mathrm{H}_{2} \mathrm{O}_{2}$ level within hippocampus $(+26.0 \%$, $p<0.05)$ and to a lesser extent within cortex $(+12.3 \%)$ and had no effect within cerebellum $(+4.7 \%)$. GSE per se significantly decreased the content of this ROS till control values, whereas ORL per se did not exert any improvement. We also determined the level of free iron, which could behave via the Fenton chemistry as a worsening pro-oxidant intracellular mediator (Table 1). $I / R$ highly increased free iron within hippocampus $(+67.0 \%, p<0.05)$ and cortex $(+34.5 \%, p<0.05)$ but paradoxically decreased it within cerebellum $(-41.3 \%$, $p<0.001)$. GSE and ORL per se efficiently corrected free iron alteration into the three compartments and no further improvement was obtained when combining both drugs (Table 1). I/R highly increased calcium within hippocampus $(+50.0 \%, p<0.001)$ and cortex $(+34.4 \%)$ and more modestly within cerebellum $(+11.8 \%)$. GSE and ORL per se decreased efficiently $\mathrm{Ca}^{2+}$ level within the three compartments and the best protection against calcium burst was obtained with the two combined drugs. 


\section{DISCUSSION}

The present paper reported the effect of I/R-induced oxidative stress and energy fueling disturbances into the brain as well as the putative protection afforded by the preventive treatment with GSE and ORL. We used the transient global ischemia model and analyzed the differential vulnerability of specific brain areas as cortex, hippocampus and cerebellum towards I/R injury. ${ }^{41}$

Among the three brain compartments, hippocampus and cortex were the most sensitive towards I/R-induced (a)

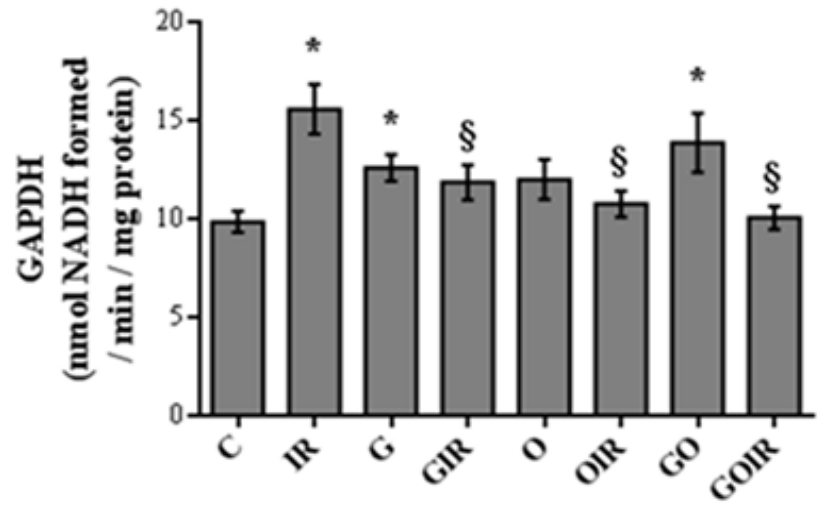

(b)

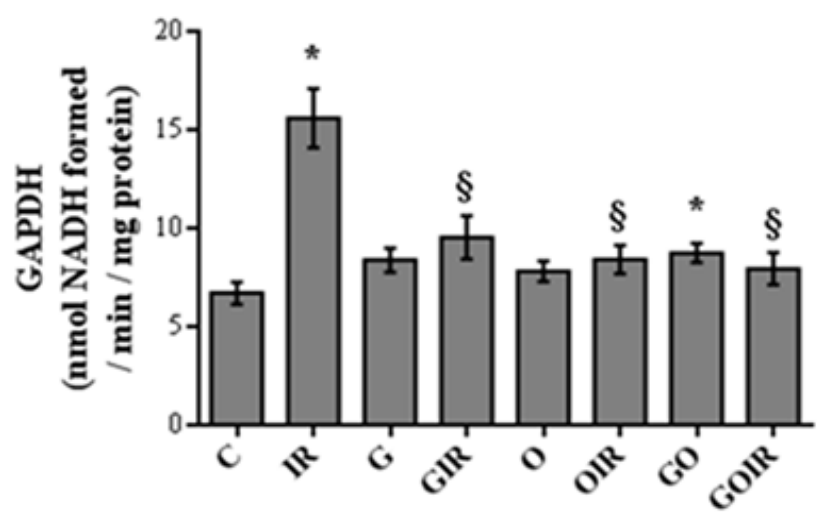

(c)

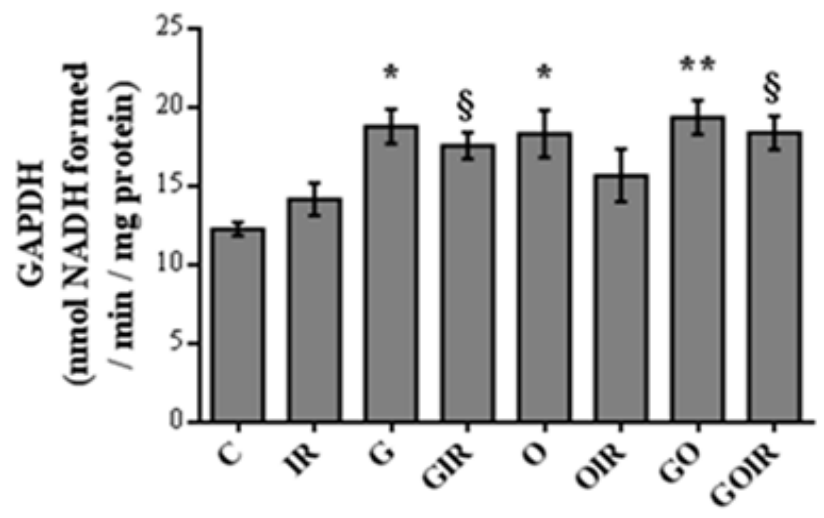

Figure 13: Effect of GSE and ORL on GAPDH activity in (a) cortex, (b) hippocampus and (c) cerebellum. ${ }^{*} p<0.05$ for IR, $\mathrm{G}, \mathrm{O}$ or $\mathrm{GO}$ versus $\mathrm{C},{ }^{* *} p<0.001$ for $\mathrm{GO}$ versus $\mathrm{C}, \S p<0.05$ for GIR, OIR or GOIR versus IR. (a)

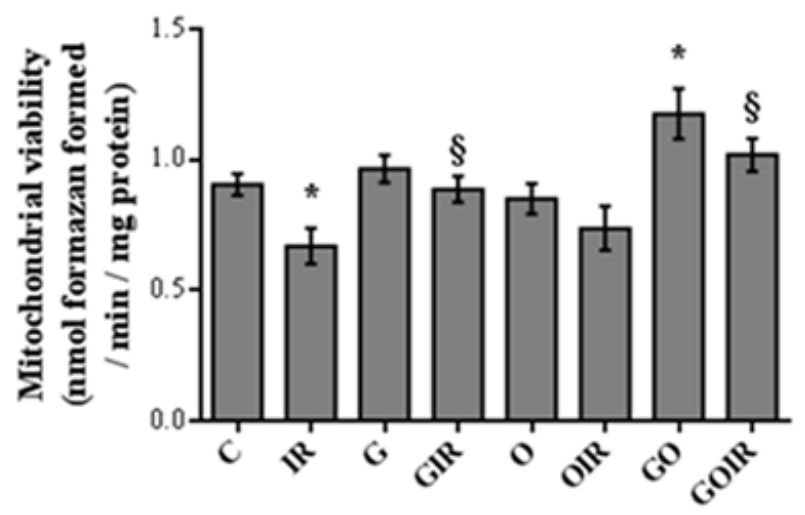

(b)

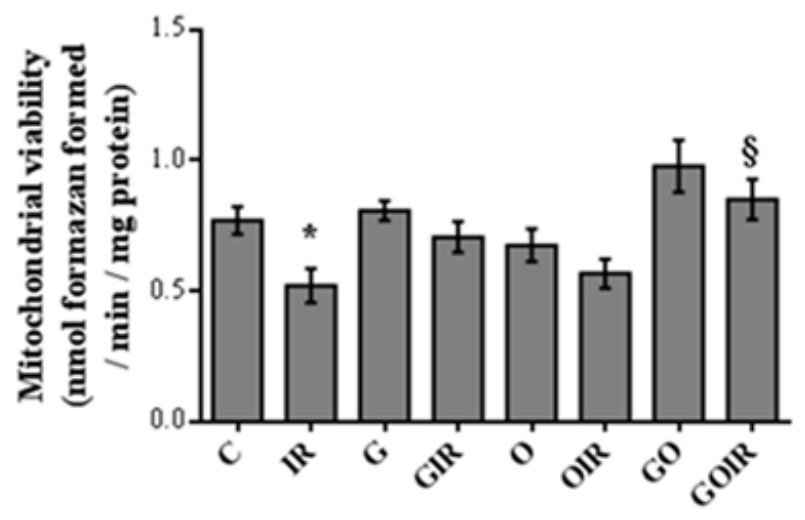

(c)

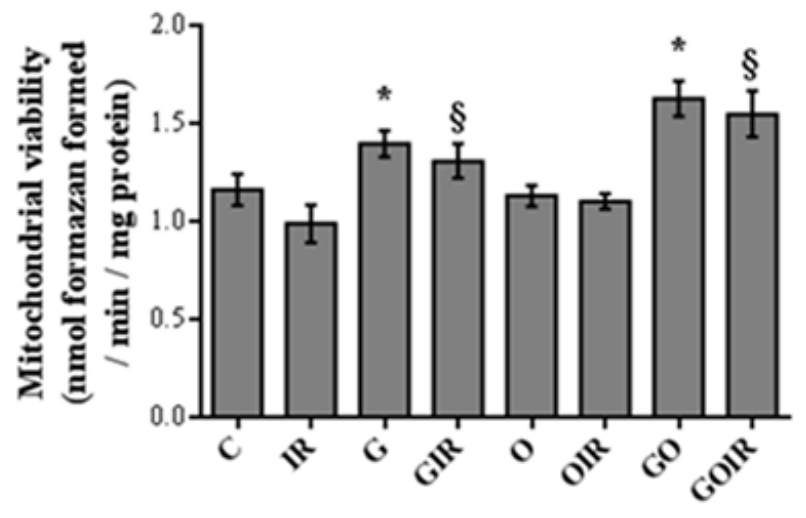

Figure 14: Effect of GSE and ORL on mitochondria survival in (a) cortex, (b) hippocampus and (c) cerebellum. ${ }^{*} p<0.05$ for IR, $\mathrm{G}$ or $\mathrm{GO}$ versus $\mathrm{C}, \S p<0.05$ for GIR or GOIR versus IR. 
Table 1: Effect of GSE and ORL on VR-induced intracellular mediators in cortex, hippocampus and cerebellum.

\begin{tabular}{|c|c|c|c|c|c|c|c|c|c|}
\hline Parameter & & C & IR & G & GIR & 0 & OIR & OG & OGIR \\
\hline \multirow{3}{*}{$\begin{array}{c}\mathrm{H}_{2} \mathrm{O}_{2} \\
\text { (nmol/mg } \\
\text { prot) }\end{array}$} & Cortex & $84.4 \pm 1.6$ & $94.7 \pm 4.6$ & $67.2 \pm 4.3^{*}$ & $75.3 \pm 4.9 \S$ & $84.4 \pm 2.1$ & $89.8 \pm 1.8$ & $67.7 \pm 2.9 *$ & $78.2 \pm 1.3 \S$ \\
\hline & Hippocampus & $96.2 \pm 3.5$ & $121.1 \pm 6.2^{*}$ & $83.0 \pm 3.1^{*}$ & $91.1 \pm 5.5^{\S}$ & $100.2 \pm 3.3$ & \begin{tabular}{|c|}
$111.5 \pm$ \\
3.5 \\
\end{tabular} & $83.2 \pm 2.1^{*}$ & $93.0 \pm 3.1 \S$ \\
\hline & & $\begin{array}{c}118.1 \pm \\
2.1\end{array}$ & $123.6 \pm 4.9$ & $90.9 \pm 4.3^{* *}$ & $100.0 \pm 4.5^{\S}$ & $119.8 \pm 1.6$ & $\begin{array}{c}121.7 \pm \\
2.8\end{array}$ & $92.0 \pm 3.8^{* *}$ & $105.1 \pm 3.4 \S$ \\
\hline \multirow{3}{*}{$\begin{array}{c}\text { Free iron } \\
\text { (nmol/mg } \\
\text { prot) }\end{array}$} & & $3.7 \pm 0.2$ & & & $3.9 \pm 0.2^{\S}$ & $3.1 \pm 0.2$ & $3.9 \pm 0.2^{\S}$ & $2.4 \pm 0.1^{* *}$ & $3.3 \pm 0.2^{\S}$ \\
\hline & Hippocampus & $1.9 \pm 0.1$ & $3.2 \pm 0.3^{*}$ & $1.6 \pm 0.1^{*}$ & $2.1 \pm 0.1^{\S}$ & $1.7 \pm 0.2$ & $2.3 \pm 0.2^{\S}$ & $1.5 \pm 0.2^{*}$ & $2.0 \pm 0.3^{\S}$ \\
\hline & Cerebellum & $4.1 \pm 0.3$ & $2.4 \pm 0.2^{* *}$ & $3.4 \pm 0.2$ & $3.3 \pm 0.1^{\S}$ & $3.6 \pm 0.2$ & $3.0 \pm 0.1^{\S}$ & $3.5 \pm 0.2$ & $3.4 \pm 0.2^{\S}$ \\
\hline \multirow{3}{*}{$\begin{array}{c}\mathrm{Ca}^{2+} \\
\text { (nmol/mg } \\
\text { prot) }\end{array}$} & Cortex & $6.3 \pm 0.7$ & $8.4 \pm 1.1$ & $4.0 \pm 0.5^{*}$ & $4.9 \pm 0.7^{\S}$ & $3.7 \pm 0.3^{*}$ & $4.6 \pm 0.7^{\S}$ & $3.1 \pm 0.8^{*}$ & $3.5 \pm 0.4^{\S}$ \\
\hline & Hippocampus & $11.6 \pm 0.4$ & $17.4 \pm 0.8^{* *}$ & $11.2 \pm 0.3$ & $13.3 \pm 0.5^{\S}$ & $9.6 \pm 0.2^{*}$ & $\begin{array}{c}10.3 \\
\pm 0.6 \S \S \\
\end{array}$ & $9.5 \pm 0.2^{*}$ & $9.7 \pm 0.5 \S \S$ \\
\hline & Cerebellum & $16.4 \pm 1.0$ & $18.3 \pm 1.1$ & $11.0 \pm 1.4^{*}$ & $12.1 \pm 1.1^{\S}$ & $10.6 \pm 0.6^{* *}$ & $11.7 \pm 1.0^{8}$ & $9.8 \pm 0.7^{* *}$ & $10.4 \pm 0.6 \S \S$ \\
\hline
\end{tabular}

* $p<0.05$ for IR, G, O or GO versus $C$, ** $p<0.001$ for IR, G, O or GO versus $C, \$ p<0.05$ for GIR, OIR or GOIR versus IR, $\$ \$ p<0.001$ for OIR or GOIR versus IR

oxidative stress. This peculiar vulnerability could be linked to the drop in antioxidant enzymes as SOD, CAT and GPx that lead to ROS overproduction as $\mathrm{H}_{2} \mathrm{O}_{2}$ or RNS as peroxynitrite. Indeed, $\mathrm{H}_{2} \mathrm{O}_{2}$ is able to inactivate $\mathrm{Cu} / \mathrm{Zn}-\mathrm{SOD}$ by oxidizing an histidine residue located in its active site. ${ }^{42}$ and peroxynitrite is a well-known inhibitor of Mn-SOD through nitrating and oxidizing a critical tyrosine residue at the enzyme active site. ${ }^{43}$

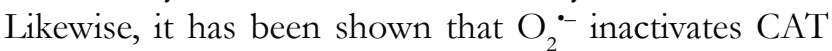
via reducing the $\mathrm{Fe}^{3+}$ of its heme groups to $\mathrm{Fe}^{2+},{ }^{44}$ and inhibits GPx by oxidizing the selenocysteine residue of its active site. ${ }^{45}$ It could also be linked to the differential effect of $\mathrm{I} / \mathrm{R}$ on free iron distribution, namely a burst within hippocampus and cortex and depletion within cerebellum. Free iron is a well-known oxidative stress worsening agent via Fenton chemistry responsible for damages to biomolecules as proteins or to the leakage of BBB leading to neuronal death and gliosis. ${ }^{46}$ Iron deficiency occurring within cerebellum may affect mitochondrial enzymes within oligodendrocytes leading to hypomyelination ${ }^{47}$ or reduction of neurotransmitters uptake by neurons. ${ }^{48}$ In this respect free iron dyshomeostasis has been linked to altered expression of transferrin receptor 1, divalent metal transporter 1, ferroportin 1, L-ferritin ${ }^{49}$ or hepcidin. ${ }^{50}$ Future studies should investigate the relevance of such proteins in I/R induced iron dyshomeostasis in cerebellum, as well as in hippocampus and cortex.

$\mathrm{I} / \mathrm{R}$ injury also affected the pro-oxidant $\mathrm{XO}$ activity mainly within hippocampus and cortex when compared to cerebellum. Indeed it has been shown that treatment of cells with a calcium chelator prevents the increase in $\mathrm{XO}$ protein expression induced by $\mathrm{H}_{2} \mathrm{O}_{2}$ and that a $\mathrm{H}_{2} \mathrm{O}_{2}$ scavenger did not affect $\mathrm{XO}$ level, suggesting that calcium and $\mathrm{H}_{2} \mathrm{O}_{2}$ are intracellular mediators implicated in the modulation of $\mathrm{XO}$ activity $^{51}$ as depicted in the present work within cortex and hippocampus versus cerebellum.

We also found that $I / R$ induces an energy failure mainly within cortex and hippocampus as it altered fueling enzymes from TCA cycle, Oxphos and ETC complexes I and II as well as glutamatergic pathway. I/R-induced oxidative stress plays a critical role in the inhibition of these metabolic enzymes containing iron-sulphur clusters which are primary sites for ROS attack. An important pathway for $\mathrm{Ca}^{2+}$ accumulation in cerebral cortex and hippocampus neurons is linked to I/Rinduced glutamatergic excitotoxicity which partly results from the decrease in GDH activity, leading to lower $\alpha$-ketoglutarate. A putative explanation for this alteration could lie in the S-palmitoylation of a cysteine residue at the GDH active site. ${ }^{52}$ Unexpectedly I/R did not drop GS activity as previously described for whole brain ${ }^{13}$ and this discrepancy is still obscure.

Moreover, our findings demonstrated that cortex and hippocampus were the most vulnerable compartments to neurodegeneration through GAPDH, a moonlighting glycolytic enzyme implicated in I/R-induced neuronal apoptosis. Overexpression of GAPDH and its subsequent nuclear translocation have been shown to mediate cell death through the activation of p53 and poly(ADP-ribose) polymerase-1 (PARP-1). ${ }^{53,54}$ GAPDH can also accumulate within mitochondria to induce a loss of the inner transmembrane potential and matrix swelling, permeabilization of the inner mitochondrial membrane and a release of pro-apoptotic proteins as cytochrome C. ${ }^{55}$ Interestingly, cerebellum was preserved from GAPDH-induced intrinsic apoptosis following transient global I/R. This can be explained by the ability of cerebellum in maintaining high level of proteins such as heme oxygenase-1 (HO-1), which protected this brain area from neuro-degeneration. Indeed, 
accumulating evidence has involved contributory roles for the metabolites produced by this detoxifying enzyme; biliverdin is a potent antioxidant compound, ${ }^{56}$ $\mathrm{Fe}^{2+}$ stimulates the expression of the cytoprotective molecule ferritin ${ }^{57}$ and carbon monoxide (CO) is a regulator of mitochondrial biogenesis and function. ${ }^{58}$ However, the implication of this enzyme and its products on the putative neuroprotection afforded to cerebellum remains to be investigated.

To our knowledge, our report is the first one to state on the neuroprotective effect of GSE and ORL association on I/R injury. GSE was used at high dosage $(2.5 \mathrm{~g} / \mathrm{kg})$ previously shown to be safe in various experimental settings, did not exert any toxic effect and protected the whole brain from I/R insult. ${ }^{13}$ ORL was used at a low dosage $(4 \mathrm{mg} / \mathrm{kg}$ ) that was safe, able to cross the BBB as shown in a rat model of high fat diet-induced obesity. ${ }^{19}$ GSE counteracted almost all I/R-induced disturbances mainly through its anti-oxidative properties as shown by its effect on protein carbonylation, $\mathrm{H}_{2} \mathrm{O}_{2}$ and free iron distribution, as well as XO, SOD, CAT and GPx activities. Our results are in agreement with several previous works dealing with the anti-oxidative effect of GSE on various pathologies associated brain disorders as obesity, ${ }^{59}$ epilepsy, ${ }^{60}$ Alzheimer's disease. ${ }^{61}$ and Parkinson's disease. ${ }^{62}$ We believe that polyphenols are mainly responsible of the beneficial effects of GSE. In fact, it is well recognized that phenolic compounds can directly reduce oxidative stress by scavenging free radicals and chelating metal ions. ${ }^{63}$ In addition, polyphenols can alleviate oxidative stress through the up regulation of cytoprotective transcription factors as nuclear factor erythroid 2-related factor 2 (Nrf2) that plays a key role in the expression of detoxifying and antioxidant enzymes. ${ }^{64}$ However, it is unclear which GSE-containing polyphenols is at the basis of such protection against I/R-induced oxidative stress and our data rather suggest this pleiotropic effect results from synergism between various GSE containing polyphenols.

Undoubtedly, the most important result drawn from this study is the supplemental protection provided by the adjunction of ORL to GSE treatment against I/R-induced energy failure. Our data showed that ORL further improved enhancement of mitochondrial Oxphos, which increases ATP production and thus neuronal survival. This beneficial effect can be explained by a high generation of NADH following the stimulation of GDH- $\alpha-\mathrm{KGDH}$ pathway. Indeed, the decrease in $\mathrm{NAD}^{+} / \mathrm{NADH}$ ratio activates the $\mathrm{NADH}$ oxidase dependent apoptosis-inducing factor (AIF) that plays an important role in $\mathrm{NADH}$ dehydrogenase
ETC complex I activity. ${ }^{65}$ Besides, glutamate oxidation through GDH increases $\alpha$-ketoglutarate pool that stimulates anabolic and catabolic reactions of Krebs cycle enzymes as succinate dehydrogenase and fumarase..$^{33}$ As far as we know, our study is the first that shows an effect of ORL on GDH- $\alpha-K G D H$ complex activity and brain energy metabolism, which constitute the link between TCA cycle and glutamate metabolism. Moreover as our data suggested that ORL improve GSE effect on I/R-induced glutamatergic excitotoxicity and neurodegeneration, it is tempting to speculate that ORL acted simultaneously as a FASN inhibitor, limiting the bioavailability of the GDH inhibitor palmitoyl-CoA ${ }^{66}$ and as a mitochondrial respiration inhibitor. ${ }^{67}$ Future work should investigate the ORL-induced stimulation of GDH activity.

\section{CONCLUSION}

In conclusion, this report shows that adjunction of ORL to GSE pretreatment is a potent strategy for the brain protection against I/R injury. GSE acts mainly through its anti-oxidative properties, while ORL exerted complementary effect on energy metabolism and glutamatergic neurotransmission and that the most efficient protection was obtained when combining both drugs. Further studies should be planned in order to determine the lipid-signaling pathways targets of ORL that cope with its neuroprotective effect.

\section{ACKNOWLEDGEMENT}

We are grateful to Mr. Ridha Charrada, head of the "Domaine Neferis" Grombalia, Tunisia, for providing us with grape pomace.

\section{CONFLICT OF INTEREST}

The authors declare no potential conflicts of interest.

\section{ABBREVIATIONS}

ADP: adenosine 5'-diphosphate; ATP: adenosine 5'-triphosphate; BBB: blood-brain barrier; BSA: bovine serum albumin; CAT: catalase; DNPH: 2,4-dinitrophenylhydrazine; DTNB: dithio-5,5'-bis(2nitro-benzoic acid); EDTA: ethylenediaminetetraacetic acid; ETC: electron Transport Chain; FASN: fatty acid synthase; FH: fumarase; GA3P: glyceraldehyde 3-phosphate; GAPDH: glyceraldehyde-3-phosphate dehydrogenase; GDH: glutamate dehydrogenase; Gln: L-glutamine; Glu: L-glutamate; GPx: glutathione peroxidase; GS: glutamine synthetase; GSE: grape 
seed extract; GSH: L-glutathione reduced; GuHCl: Guanidine hydrochloride; $\mathbf{H}_{2} \mathbf{O}_{2}$ : hydrogen peroxide; I/R: ischemia/reperfusion; $\mathbf{K C N}$ : Potassium cyanide; MTT: 3-(4,5-dimethylthiazol-2-yl)-2,5diphenyltetrazolium bromide; $\mathbf{N A D}^{+}$: $\beta$-nicotinamide adenine dinucleotide oxidized; NADH: $\beta$-nicotinamide adenine dinucleotide reduced; ORL: orlistat; Oxphos: mitochondrial oxidative phosphorylation; RNS: reactive nitrogen specie; ROS: reactive oxygen species; SOD: superoxide dismutase; TCA: trichloroacetic acid; TTC: 2,3,5-triphenyltetrazolium chloride; XO: xanthine oxidase; $\alpha$-kG: $\alpha$-ketoglutarate; $\alpha-\mathbf{K G D H}$ : $\alpha$-ketoglutarate dehydrogenase.

\section{REFERENCES}

1. World Health Organization, 2018. Available from: https://www.who.int/newsroom/fact-sheets/detail/the-top-10-causes-of-death

2. Miller EL, Murray L, Richards L, Zorowitz RD, Bakas T, Clark P, et al. Comprehensive overview of nursing and interdisciplinary rehabilitation care of the stroke patient: A scientific statement from the American Heart Association. Stroke. 2010;41(10):2402-48.

3. Gomes J, Wachsman MA. Handbook of Clinical Nutrition and Stroke. New York, NY: Springer. 2013;15-32.

4. Dirnagl U, ladecola C, Moskowitz MA. Pathobiology of ischaemic stroke: An integrated view. Trends Neurosci. 1999;22(9):391-7.

5. Bai J, Lyden PD. Revisiting cerebral postischemic reperfusion injury: New insights in understanding reperfusion failure, hemorrhage and edema. Int J Stroke. 2015;10(2):143-52.

6. Evans $\mathrm{PH}$. Free radicals in brain metabolism and pathology. $\mathrm{Br}$ Med Bull. 1993;49(3):577-87.

7. FDA. Agency Response Letter GRAS Notice No. GRN 000124, 2003. Available from: https://wayback.archive-it.org/7993/20171031022531/https:// www.fda.gov/Food/IngredientsPackagingLabeling/GRAS/Noticelnventory/ ucm153940.htm.

8. Ky I, Lorrain B, Kolbas N, Crozier A, Teissedre PL. Wine by-products: phenolic characterization and antioxidant activity evaluation of grapes and grape pomaces from six different French grape varieties. Molecules. 2014;19(1):482-506

9. Akaberi M, Hosseinzadeh H. Grapes (Vitis vinifera) as a Potential Candidate for the Therapy of the Metabolic Syndrome. Phytother Res. 2016;30(4):54056 .

10. Charradi K, Elkahoui S, Karkouch I, Limam F, BenHassine F, EIMay MV, et al. Protective effect of grape seed and skin extract against high-fat diet-induced liver steatosis and zinc depletion in rat. Dig Dis Sci. 2014;59(8):1768-78.

11. Turki K, Charradi K, Boukhalfa H, Belhaj M, Limam F, Aouani E. Grape seed powder improves renal failure of chronic kidney disease patients. EXCLI J. 2016;15:424-33

12. Charradi K, Sebai H, Elkahoui S, Hassine BF, Limam F, Aouani E. Grape seed extract alleviates high-fat diet-induced obesity and heart dysfunction by preventing cardiac siderosis. Cardiovasc Toxicol. 2011;11(1):28-37.

13. Safwen K, Selima S, Mohamed E, Ferid L, Pascal C, Mohamed A, et al. Protective effect of grape seed and skin extract on cerebral ischemia in rat: Implication of transition metals. Int J Stroke. 2015;10(3):415-24.

14. Kadri S, ElAyed M, Cosette $\mathrm{P}$, Jouenne $\mathrm{T}$, Elkhaoui $\mathrm{S}$, Zekri $\mathrm{S}$, et al. Neuroprotective effect of grape seed extract on brain ischemia: A proteomic approach. Metab Brain Dis. 2019;34(3):889-907.

15. US Food and Drug Administration. 1999. Available from: https://www. accessdata.fda.gov/drugsatfda_docs/nda/99/020766a_xenical_appltr.pd

16. Kiortsis DN, Filippatos TD, Elisaf MS. The effects of orlistat on metabolic parameters and other cardiovascular risk factors. Diabetes Metab. 2005;31(1):15-22.
17. Zakia BA, Kavimani S. Effect of Orlistat on learning and memory in normal and memory deficit animals. Int J Pharm Pharm Sci. 2015;7(5):130-3.

18. Du J, Wang Z. Therapeutic potential of lipase inhibitor orlistat in Alzheimer's disease. Med Hypotheses. 2009;73(5):662-3.

19. Mahmoudi M, Charradi K, Limam F, Aouani E. Grape seed and skin extract as an adjunct to xenical therapy reduces obesity, brain lipotoxicity and oxidative stress in high fat diet fed rats. Obes Res Clin Pract. 2018;12(Suppl 2):S115-26

20. Smith ML, Bendek G, Dahlgren N, Rosén I, Wieloch T, Siesjö BK. Models for studying long-term recovery following forebrain ischemia in the rat. 2. A 2-vessel occlusion model. Acta Neurol Scand. 1984;69(6):385-401.

21. Gornall AG, Bardawill CJ, David MM. Determination of serum proteins by means of the biuret reaction. J Biol Chem. 1949;177(2):751-66.

22. Liang LP, Patel M. Iron-sulfur enzyme mediated mitochondrial superoxide toxicity in experimental Parkinson's disease. J Neurochem. 2004;90(5):107684.

23. Bradford MM. A rapid and sensitive method for the quantitation of microgram quantities of protein utilizing the principle of protein-dye binding. Anal Biochem. 1976;72(1-2):248-54.

24. Wehr NB, Levine RL. Quantification of protein carbonylation. Methods Mol Biol. 2013;965:265-81.

25. Prajda N, Weber G. Malignant transformation-linked imbalance: Decreased xanthine oxidase activity in hepatomas. FEBS Letters. 1975;59(2):245-9.

26. Aebi H. Catalase in vitro. Methods Enzymol. 1984;105:121-6.

27. Flohé L, Günzler WA. Assays of glutathione peroxidase. Methods Enzymol. 1984;105:114-20.

28. Misra HP, Fridovich I. The role of superoxide anion in the autoxidation of epinephrine and a simple assay for superoxide dismutase. J Biol Chem. 1972;247(10):3170-5

29. Massey $\mathrm{V}$. The composition of the ketoglutarate dehydrogenase complex. Biochim Biophys Acta. 1960;38:447-60.

30. Racker E. Spectrophotometric measurements of the enzymatic formation of fumaric and cis-aconitic acids. Biochim Biophys Acta. 1950;4(1-3):211-4

31. Hatefi Y. Preparation and properties of $\mathrm{NADH}$ : Ubiquinone oxidoreductase (complex I), EC 1.6.5.3. Methods Enzymol. 1978;53:11-4

32. King TE. Preparation of succinate dehydrogenase and reconstitution of succinate oxidase. Methods Enzymol. 1967;10:322-31.

33. Kim AY, Jeong $\mathrm{KH}$, Lee JH, Kang Y, Lee SH, Baik EJ. Glutamate dehydrogenase as a neuroprotective target against brain ischemia and reperfusion. Neuroscience. 2017;340:487-500

34. Minet R, Villie F, Marcollet M, Meynial-Denis D, Cynober L. Measurement of glutamine synthetase activity in rat muscle by a colorimetric assay. Clin Chim Acta. 1997;268(1-2):121-32

35. Krebs EG. Glyceraldehyde-3-phosphate dehydrogenase from yeast. Methods Enzymol. 1955;1:407-11.

36. Liu Y, Peterson DA, Kimura H, Schubert D. Mechanism of cellular 3-(4,5-dimethylthiazol-2-yl)-2,5-diphenyltetrazolium bromide (MTT) reduction. J Neurochem. 1997;69(2):581-93.

37. Bederson JB, Pitts LH, Germano SM, Nishimura MC, Davis RL, Bartkowski HM. Evaluation of 2,3,5-triphenyltetrazolium chloride as a stain for detection and quantification of experimental cerebral infarction in rats. Stroke. 1986;17(6):1304-8.

38. Trinder P. Determination of blood glucose using an oxidase-peroxidase system with a non-carcinogenic chromogen. J Clin Pathol. 1969;22(2):15861

39. Leardi A, Caraglia M, Selleri C, Pepe S, Pizzi C, Notaro R, et al. Desferioxamine increases iron depletion and apoptosis induced by ara-C of human myeloid leukaemic cells. Br J Haematol. 1998;102(3):746-52.

40. Stern J, Lewis $\mathrm{WH}$. The colorimetric estimation of calcium in serum with ocresolphthalein complexone. Clin Chim Acta. 1957;2(6):576-80.

41. Pfisterer $\mathrm{U}$, Khodosevich K. Neuronal survival in the brain: Neuron typespecific mechanisms. Cell Death Dis. 2017;8(3):e2643.

42. Uchida K, Kawakishi S. Identification of oxidized histidine generated at the active site of $\mathrm{Cu}, \mathrm{Zn}$-superoxide dismutase exposed to $\mathrm{H}_{2} \mathrm{O}_{2}$. Selective generation of 2-oxo-histidine at the histidine 118. J Biol Chem. 1994;269(4):2405-10 
43. MacMillan-Crow LA, Crow JP, Thompson JA. Peroxynitrite-mediated inactivation of manganese superoxide dismutase involves nitration and oxidation of critical tyrosine residues. Biochemistry. 1998;37(6):1613-22.

44. Shimizu N, Kobayashi K, Hayashi K. The reaction of superoxide radical with catalase. Mechanism of the inhibition of catalase by superoxide radical. J Biol Chem. 1984;259(7):4414-8.

45. Blum J, Fridovich I. Inactivation of glutathione peroxidase by superoxide radical. Arch Biochem Biophys. 1985;240(2):500-8.

46. Kondo Y, Ogawa N, Asanuma M, Ota Z, Mori A. Regional differences in lateonset iron deposition, ferritin, transferrin, astrocyte proliferation and microglial activation after transient forebrain ischemia in rat brain. J Cereb Blood Flow Metab. 1995;15(2):216-26.

47. Beard JL, Wiesinger JA, Connor JR. Pre- and postweaning iron deficiency alters myelination in Sprague-Dawley rats. Dev Neurosci. 2003;25(5):308-15.

48. Burhans MS, Dailey C, Beard Z, Wiesinger J, Murray-Kolb L, Jones BC, et al. Iron deficiency: Differential effects on monoamine transporters. Nutr Neurosci. 2005;8(1):31-8.

49. Li Y, Yu P, Chang SY, Wu Q, Yu P, Xie C, et al. Hypobaric Hypoxia Regulates Brain Iron Homeostasis in Rats. J Cell Biochem. 2017;118(6):1596-605.

50. Ding $\mathrm{H}$, Yan CZ, Shi H, Zhao YS, Chang SY, Yu P, et al. Hepcidin is involved in iron regulation in the ischemic brain. PLoS One. 2011;6(9):e25324.

51. McNally JS, Saxena A, Cai H, Dikalov S, Harrison DG. Regulation of xanthine oxidoreductase protein expression by hydrogen peroxide and calcium. Arterioscler Thromb Vasc Biol. 2005;25(8):1623-8.

52. Son HJ, Ha SC, Hwang EY, Kim EA, Ahn JY, Choi SY, et al. Roles of cysteine residues in the inhibition of human glutamate dehydrogenase by palmitoylCoA. BMB Rep. 2012;45(12):707-12.

53. Zhai D, Chin K, Wang M, Liu F. Disruption of the nuclear p53-GAPDH complex protects against ischemia-induced neuronal damage. Mol Brain. 2014;7(1):20.

54. Nakajima H, Kubo T, Ihara H, Hikida T, Danjo T, Nakatsuji M, et al. Nucleartranslocated Glyceraldehyde-3-phosphate Dehydrogenase Promotes Poly(ADP-ribose) Polymerase-1 Activation during Oxidative/Nitrosative Stress in Stroke. J Biol Chem. 2015;290(23):14493-503.

55. Tarze A, Deniaud A, LeBras M, Maillier E, Molle D, Larochette N, et al. GAPDH, a novel regulator of the pro-apoptotic mitochondrial membrane permeabilization. Oncogene. 2007;26(18):2606-20.

56. Pachori AS, Smith A, McDonald P, Zhang L, Dzau VJ, Melo LG. Hemeoxygenase-1-induced protection against hypoxia/reoxygenation is dependent on biliverdinreductase and its interaction with PI3K/Akt pathway. J Mol Cell Cardiol. 2007;43(5):580-92

57. Gonzales S, Erario MA, Tomaro ML. Heme oxygenase-1 induction and dependent increase in ferritin: A protective antioxidant stratagem in hemintreated rat brain. Dev Neurosci. 2002;24(2-3):161-8.

58. Piantadosi CA, Carraway MS, Babiker A, Suliman HB. Heme oxygenase-1 regulates cardiac mitochondrial biogenesis via Nrf2-mediated transcriptional control of nuclear respiratory factor-1. Circ Res. 2008;103(11):1232-40.

59. Charradi K, Elkahoui S, Karkouch I, Limam F, Hassine FB, Aouani E. Grape seed and skin extract prevents high-fat diet-induced brain lipotoxicity in rat. Neurochem Res. 2012;37(9):2004-13.

60. Zhen J, Qu Z, Fang H, Fu L, Wu Y, Wang H, et al. Effects of grape seed proanthocyanidin extract on pentylenetetrazole-induced kindling and associated cognitive impairment in rats. Int J Mol Med. 2014;34(2):391-8.

61. Lian Q, Nie Y, Zhang X, Tan B, Cao H, Chen W, et al. Effects of grape seed proanthocyanidin on Alzheimer's disease in vitro and in vivo. Exp Ther Med. 2016;12(3):1681-92.

62. Ben YS, Brisson G, Doucet-Beaupré H, Castonguay AM, Gora C, Amri M, et al. Neuroprotective benefits of grape seed and skin extract in a mouse model of Parkinson's disease. Nutr Neurosci. 2019;1-15.

63. Cherrak SA, Mokhtari-Soulimane N, Berroukeche F, Bensenane B Cherbonnel $\mathrm{A}$, Merzouk $\mathrm{H}$, et al. In vitro Antioxidant versus Metal Ion Chelating Properties of Flavonoids: A Structure-Activity Investigation. PLoS One. 2016;11(10):e0165575.

64. Han J, Wang M, Jing X, Shi H, Ren M, Lou H. (-)-Epigallocatechingallate protects against cerebral ischemia-induced oxidative stress via Nrf2/ARE signaling. Neurochem Res. 2014;39(7):1292-9.

65. Yang C, Ko B, Hensley CT, Jiang L, Wasti AT, Kim J, et al. Glutamine oxidation maintains the TCA cycle and cell survival during impaired mitochondrial pyruvate transport. Mol Cell. 2014;56(3):414-24.

66. Son HJ, Ha SC, Hwang EY, Kim EA, Ahn JY, Choi SY, et al. Roles of cysteine residues in the inhibition of human glutamate dehydrogenase by palmitoylCoA. BMB Rep. 2012;45(12):707-12.

67. Rossato FA, Zecchin KG, LaGuardia PG, Ortega RM, Alberici LC, Costa $\mathrm{RA}$, et al. Fatty acid synthase inhibitors induce apoptosis in non-tumorigenic melan-a cells associated with inhibition of mitochondrial respiration. PLoS One. 2014;9(6):e101060.

\section{PICTORIAL ABSTRACT}

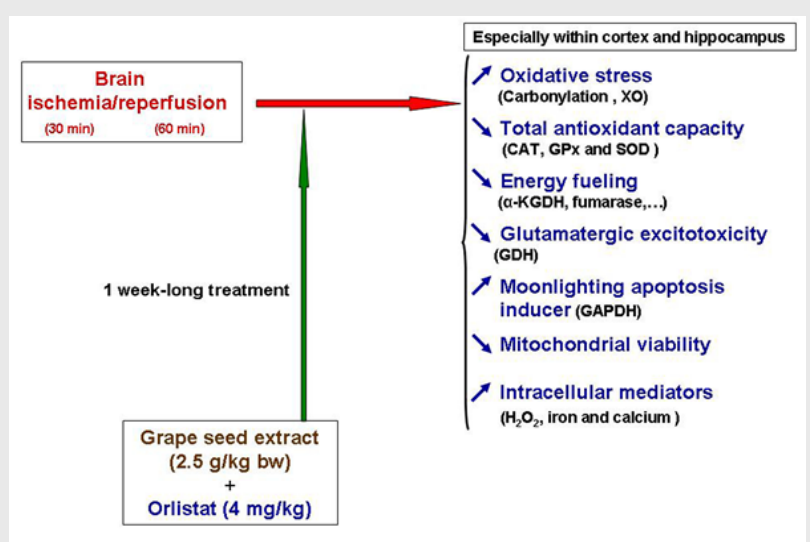

\section{SUMMARY}

The manuscript deals with the synergistic protective effect of (ORL + GSE) on the deleterious effect of brain I/R injury especially within cortex, hippocampus and cerebellum area.

\section{About Authors}

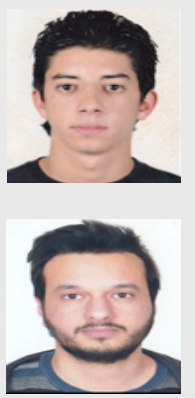

Dr. Slim Ghrir, Laboratory of Bioactive Substances, Center of Biotechnology of Borj-Cedria, BP 901, Hammam-lif 2050, Tunisia.

Dr. Wassim Ben Abbes, Laboratory of Bioactive Substances, Center of Biotechnology of Borj-Cedria, BP 901, Hammam-lif 2050, Tunisia.

Dr. Kamel Charradi, Laboratory of Bioactive Substances, Center of Biotechnology of Borj-Cedria, BP 901, Hammam-lif 2050, Tunisia.

Dr. Salem Elkahoui, Laboratory of Bioactive Substances, Center of Biotechnology of Borj-Cedria, BP 901, Hammam-lif 2050, Tunisia. 
Prof. Ferid Limam, Laboratory of Bioactive Substances, Center of Biotechnology of Borj-Cedria, BP 901, Hammam-lif 2050, Tunisia.
Prof. Ferid Limam, Laboratory of Bioactive Substances, Center of Biotechnology of Borj-Cedria, BP 901, Hammam-lif 2050, Tunisia.

Cite this article: Ghrir S, Abbes WB, Charradi K, Elkahoui S, Limam F, Aouani E. Adjunction of the Lipase Inhibitor Orlistat Improves Grape Seed Extract Neuroprotection against Brain Ischemia/Reperfusion Injury in Rats. Indian J of Pharmaceutical Education and Research. 2021;55(2):527-43. 